\title{
The construction of viewpoint aspect. The imperfective revisited
}

María J. Arche

University of Greenwich

\begin{abstract}
This paper argues for a constructionist approach for Aspect by exploring the idea that viewpoint aspect does not exert any altering force on the situation aspect properties of predicates. The proposal is developed by analyzing the point of view where conflicts between situation and viewpoint aspect have been argued to appear in previous literature, namely, the imperfective. The paper focuses on the syntax and semantics of the imperfective, which has been attributed a coercer role as a de-telicizer and de-stativizer in the progressive reading, and as a de-eventizizer in the so-called ability (or attitudinal) and habitual readings. This paper proposes that this is not necessary and provides a unified semantics for the imperfective preserving the properties of eventualities throughout the derivation. The article defends that the semantics of viewpoint aspect is encoded in functional heads containing interval-ordering predicates and quantifiers. This richer structure allows us to analyze aspectual forms with in principle contradictory content such as perfective and progressive, which sheds light onto other issues such as the understanding of non-culminating accomplishments. The proposed syntax is argued to have a corresponding explicit morphology in languages such as Spanish and a non-differentiating one in languages such as English, while the syntax-semantics underlying both of these languages is argued to be the same.
\end{abstract}

Keywords: Aspect, Imperfective, Perfective, Progressive, Coercion, SyntaxMorphology mapping

Impf:Imperfect; Pfve:perfective; 3ps: third person singular; 1ps: first person singular; VP: Verb Phrase;

\section{Introduction}

Although viewpoint aspect has been argued to be independent from the other aspectual realm known as situation aspect (also called lexical or inner aspect) by many authors (Smith 1991, Bertinetto 2000, Borik \& Reinhart 2004, Bohnemeyer $\&$ Swift 2004), others have defended that viewpoint aspect properties follow from the semantic type of the verb (Herweg 1991) and can affect and modify situation aspect properties, working as a coercive mechanism (Dowty 1979, Kamp \& Rohrer 1983; Bertinetto 1994, de Swart 1998). In this work I analyze viewpoint aspect and address its relation with situation aspect properties. I argue that viewpoint aspect is construed in the syntax via a set of functional projections containing interval-ordering predicates (Zagona 1990, Stowell 1993, 2007; Klein 1994, 2009; Demirdache \& Uribe-Etxebarria 2000, 2007) and quantifiers over occasions (Verkuyl 1999) and that these functional projections exert no altering force on the properties of situation aspect of the predicates. In the spirit of proposals such as the one by Borer (2005, to appear), the perspective taken here is that if a certain combination occurs in the syntax an interpretation will be given to it. 
To develop this proposal I focus on the analysis of the point of view where conflicts between situation and viewpoint aspect have most often been argued to present themselves: the imperfective. I analyze the syntax, semantics and morphological expression of the imperfective readings known in the literature as progressive, habitual and continuous, and discuss the role that viewpoint aspect has been argued to play in transforming the properties of the predicates it combines with in these cases. Taking Spanish as the language of analysis, I deal with the following classical issues. (i) The role of the progressive as a tool to detelicize VP predicates. Differing from previous accounts (Vlach 1981, Moens 1987, Parsons 1990, Borer 2005, among others), I will propose that the progressive does not alter situation aspect properties, as the predicate can be proved to keep its heterogeneous (i.e. non atelic) properties. The analysis of the progressive will also allow me to disentangle imperfectivity from progressivity. I will show that the progressive can also be part of perfective viewpoint and discuss the properties of "perfective progressives", where the progressive appears with the auxiliary copula aspectually inflected in perfective. I argue that such forms are precious to probe into the syntactic analysis of aspect, as they point to the need of having more than one aspectual head (one for the auxiliary verb and another for the -ing form of the verb). Also, their equivalence in Spanish to some inflected perfectives adds light onto the analysis of incomplete accomplishments. (ii) The role of the progressive to de-stativize VP predicates. The progressive has been considered not to combine with states since at least Lackoff 1966. The cases where states appear in the progressive (e.g. I am loving it) are often explained by arguing that the event type (state) has undergone a shift, thus becoming an event; having become an event, the good combination with the progressive follows. I will argue that the event type is not transformed and the predicate retains its stative properties all the way through the derivation. (iii) I also discuss the role attributed to the imperfective to de-eventize or de-dynamicize eventive VPs. Cases in point are those where the interpretation of allegedly eventive (e.g. dynamic) predicates abstracts away from actual instantiations of the event and the only assertion regards the capacity of a subject of performing such an action -the attitudinal reading (e.g. That old model of printer printed 10 pages per minute only). In this context, I show that modifiers associated with eventive structure (e.g. in-time modifiers) can still appear in the so-called ability readings, which I take as an indication that the properties of the predicate have not transformed into a stative structure. (iv) Finally, I revisit the idea that habitual viewpoint can work as an operation that turns all predicates into states allowing them to combine with modifiers that arguably are only possible with atelic predicates, such as foradverbials: John played the sonata for eight hours. I show that the event type is preserved and the for-adverbial has a different syntactic position than the one it occupies when it refers to the duration of a single instantiation of the event.

In sum, I argue that proposing destruction of telicity, stativity or eventiveness is neither satisfactory nor necessary and I explore an approach according to which predicates keep their properties throughout the derivation. In carrying out this agenda I examine other fundamental questions such as the correspondences between forms and semantic components that delineate the fundamental differences between the imperfect and the perfective and the nature of viewpoint aspect heads. In this regard, I discuss whether viewpoint aspect projections are headed by quantifiers (Bonomi 1997, Cipriá \& Roberts 2000, Menéndez-Benito 2002) or by interval ordering predicates (Klein 1994, 2009; Demirdache \& Uribe- 
Etxebarria 2000, 2004, 2007). I show that viewpoint structure is in fact complex and contains both quantificational heads and interval ordering predicates. I furthermore show that the element that is uniformly present in all expressions of imperfectivity is the interval-ordering predicate (with the content of "within"), which is morphologically expressed through inflection.

This article is organized as follows. In section 2, I provide a succinct presentation of the assumptions I make and the toolkit I will use to develop the formal account of the construction of aspect. Section 3 presents an analysis about the progressive and the fundamental distinction between (a)telicity and (im)perfectivity as well as about the association between imperfectivity and progressivity. Section 4 focuses on the construction of the so-called continuous viewpoint, dealing with two opposite issues: the combination of states with the progressive, which makes them look as dynamic events, and the combination of events with structure that makes them look as states (yielding the interpretation known as attitudinal). Section 5 analyzes habitual viewpoint, argued to combine with any kind of predicate. Section 6 presents a number of considerations regarding the relations between semantics and morpho-syntax across languages. Section 7 closes the paper with conclusions and consequences of the analysis for other linguistic areas such as acquisition.

\section{Aspect. Theoretical toolkit}

Since the literature in Aspect is vast and authors ascribe different meanings to the same theoretical constructs I devote this section to lay out the fundamental theoretical lines and vocabulary that I will assume for both viewpoint and situation aspect.

Regarding situation aspect, I assume that its properties are decided in the syntax, in line with recent work (Ritter \& Rosen 2000, Borer 2005, Ramchand 2008). Following Borer (2005) for concreteness, I assume that verbal predicates enter the derivation as roots and obtain the fundamental properties regarding situation aspect by combining with the relevant syntactic projections. I contend that the fundamental difference in the realm of situation aspect is that of homogeneity vs. heterogeneity. With Borer (2005) I assume that predicates are homogeneous by default and become heterogeneous by virtue of their combination with a projection that makes the predicate divisive (e.g. by a projection such as Quantity). Thus, predicates are heterogeneous (or quantity) if they are not homogeneous. Predicates are homogeneous if and only if they are both cumulative and divisive, as defined in (1) and (2).

(1) Cumulative

$\mathrm{P}$ is cumulative iff $\forall \mathrm{x}, \mathrm{y}[\mathrm{P}(\mathrm{x}) \& \mathrm{P}(\mathrm{y}) \rightarrow \mathrm{P}(\mathrm{x} \cup \mathrm{y})]$

$\mathrm{P}$ is cumulative iff for all $\mathrm{x}$ and $\mathrm{y}$ with property $\mathrm{P}$, the union of $\mathrm{x}$ and $\mathrm{y}$ also has property $\mathrm{P}$.

(2) Divisive

$\mathrm{P}$ is divisive iff $\forall \mathrm{x}[\mathrm{P}(\mathrm{x}) \rightarrow \exists \mathrm{y}[\mathrm{P}(\mathrm{y}) \& \mathrm{y}<\mathrm{x}] \& \forall \mathrm{x}, \mathrm{y}[\mathrm{P}(\mathrm{x}) \& \mathrm{P}(\mathrm{y}) \& \mathrm{y}<\mathrm{x} \rightarrow$ $\mathrm{P}(\mathrm{x}-\mathrm{y})]]$ 
$\mathrm{P}$ is divisive iff for all $\mathrm{x}$ with property $\mathrm{P}$ there is a proper part $\mathrm{y}$ of $\mathrm{x}$ which also has property $\mathrm{P}$, and for all $\mathrm{x}$ and $\mathrm{y}$ with property $\mathrm{P}$ if $\mathrm{y}$ is a proper part of $\mathrm{x}$ then the subtraction of $\mathrm{y}$ from $\mathrm{x}$ also has property $\mathrm{P}$.

In Borer's framework any root can combine with any aspectual projection, yielding the aspectual make up of the verbal predicate. For this author, activities are the default event type, as they ensue in the absence of quantity structure. States, on the contrary, are hypothesized to emerge in the presence of stative structure. I argue that a similar constructionist view explains viewpoint aspect. The interpretation of the sentence depends on whether the predicate merges with a particular functional viewpoint head. In this sense, this proposal differs from others such as Kamp \& Rohrer's 1983, Hinrichs' 1986 and Herweg's 1991, where aspectual forms were assumed to describe specific types of predicates and to follow from the situation aspect properties of predicates (e.g. French Imparfait for states; Passé Simple for events). According to the proposal defended in this paper, the situation properties gained in the syntax remain unaltered, viewpoint aspect heads having no power whatsoever to change them. As a consequence, coercion mechanisms as reinterpretation mechanisms that come into play when there is a conflict between aspectual properties of eventualities and aspectual operators (Herweg 1991, de Swart 1998) are claimed not to exist as such. We could say that in the approach explored here the syntactic structure is a pure coercive mechanism; importantly, however, it does not work as an operation that intervenes to "solve conflicts", but only to create meaning. Thus, viewpoint aspect heads take the predicate with whatever situation aspect properties as input and give a viewpoint aspect interpretation as a result. This perspective does not amount to saying that all combinations are expected to be equally natural, but that, if they are given, viewpoint aspect heads will not change the properties of the event type.

As for the formal study of viewpoint aspect, the technical framework assumed here is based on the one developed by Zagona (1990), Stowell (1993, 1996, 2007), Klein (1994) and Demirdache and Uribe-Etxebarria (2000, 2004, 2007, this issue). Taking as a point of departure the primitives proposed by Reichenbach (1947), namely, a finite set of intervals and a finite set of possible relations, these authors have elaborated a formal framework where the temporal and aspectual relations are rendered to the same primitives and the relations between the intervals are derived from independently founded principles of the grammar. In this framework, temporal and aspectual interpretation is obtained by virtue of the relations that intervals of time establish between each other. Such relationships are established by the syntactic categories of Tense and Aspect. Tense and Aspect are conceived as dyadic predicates containing the same semantic primitives (Demirdache \& Uribe-Etxebarria 2000); the difference between them resides in the intervals they order. Specifically, the semantic content of Tense and Aspect is defined in topological terms (Hale 1984) and described as ordering predicates "after", "before" or "within". The set of intervals Tense and Aspect order consists of: a Reference Time (RefT), whose reference is the Speech Time in matrix clauses; the Event Time (EvT), defined as the interval the situation occupies; and Assertion Time (AT), which is the time that the sentence refers to. Along lines similar to Partee (1973), Klein argues that clauses make assertions about a specific interval and it is this interval, rather than the EvT, that is ordered with respect to the reference time by Tense. That is, in an example like (3), Tense does not order the whole interval that the situation of watching the 
game extends over in the past; rather, (3) makes a claim about a particular interval, for example, the interval modified by when I entered the room, ${ }^{1}$ and this is the interval that is located in the past. The remainder of the interval the eventuality may have extended over, in Klein's view, is not taken into account.

(3) Bill was watching the game

In line with Zagona (op. cit), Stowell (op. cit) and Demirdache and UribeEtxebarria (op.cit), I will consider that the intervals that Tense and Aspect order are represented in the syntax, which captures the impact of sentential syntax on temporal interpretation that has been observed since Enç 1987. In particular, I will assume a structure such as the one represented below as a hypothesis for the discussion. The structure in (4) aims to capture a configurational relationship among the elements that play a role in the Tense-Aspect interpretation.

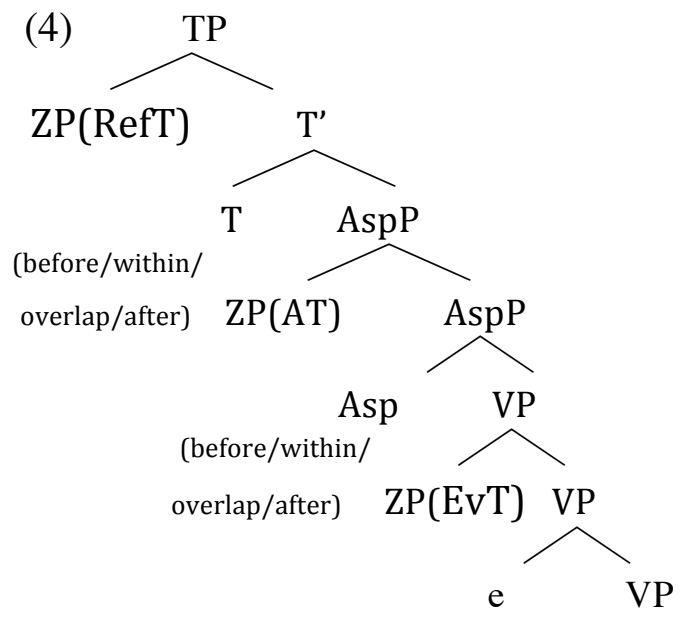

According to this representation, the semantic content of Tense and Aspect consists of dyadic ordering predicates. Tense orders the Assertion Time (AT) with respect to a Reference Time (in the sense of pure time taken as a reference to order, e.g. speech time in main clauses). Aspect orders the AT with respect to the Event Time (EvT). As for the syntactic nature of the time denoting intervals, based on Stowell (op. cit.), I will consider them as Zeit Phrases (ZPs), time phrases, with a structure analogous to DPs', which can enter in similar syntactic relations governed by the same independent principles of grammar. The RefT gets its content either from the context of conversation to refer to the speech time or is bound by the main EvT in a compound clause. I will assume that the Assertion Time as an interval that picks out its content from the salient discourse. ${ }^{2}$ I will follow Demirdache \& Uribe-Etxebarria (2000, this issue) in that Tense and Aspect involve the same ordering predicates and the difference lies in the time argument they take. The predicate "before" yields future tense and prospective aspectual interpretation (5); "after" yields past tense and perfect aspect (6); "within" gives

\footnotetext{
${ }^{1}$ Following Demirdache and Uribe-Etxebarria 2004 I take it that the adverbial modifies the AT and a relation of central coincidence is established between them. In Yesterday Mary called, the AT is included within the interval denoted by the adverbial yesterday. See Demirdache and UribeEtexbarria 2004 for details and discussion.

${ }^{2}$ The relation between the Assertion Time and the contextual background is taken to be anaphoric, along the lines of von Fintel (1994). According to this author the background context contains the set where anaphoric elements and free variables find their antecedents.
} 
present tense and imperfective aspect as a result respectively; and "total overlap" can be considered to yield perfective aspect (7).

(5) Bill is going to watch the game

(6) Bill has watched the game

(7) Bill watched the game

I will take the fundamental insights from Klein et al (2000) and Klein (2009) concerning the descriptions of the time predicates as per below. ${ }^{3}$

Table 1. Aspect firms and ordering predicates

\begin{tabular}{|l|c|c|c|}
\hline Aspect form & & \multicolumn{2}{|c|}{ Predicate } \\
\hline Imperfective & \multirow{3}{*}{ Assertion Time } & (WITH)IN & \multirow{2}{*}{ Event Time } \\
Perfective & & (Total) OVERLAP & \\
Perfect & & AFTER & \\
Prospective & & BEFORE & \\
\hline
\end{tabular}

In this paper I am going to focus on the syntax and semantics of the imperfective using its contrast with the perfective as an analytical tool. I am going to argue that the ordering predicate within underlies a variety of readings commonly associated with the imperfective (e.g. progressive, habitual, continuous). ${ }^{4,5}$ The interpretations commonly found in the literature as 'unfinished' (imperfective) and 'finished' (perfective) are accounted for here as a consequence of different interval orderings. This way, such traditional descriptions or more recent ones, such as Smith's (1991), whereby the imperfective and the perfective contrast according to whether the situation is viewed partially or in its entirety, receive a formal account. ${ }^{6}$

\footnotetext{
${ }^{3}$ Following common practice I will use the terms "imperfective" and "perfective" to refer to the semantic content and capitalized "Imperfect" and "Perfective" to refer to the morphological forms found in Spanish.

${ }^{4}$ See Demirdache \& Uribe-Etxebarria (2011) for another view on the imperfective within this same theoretical model. These authors restrict the predicate of inclusion to the progressive and do not conceive the imperfective/perfective dichotomy as based on a different predicate. Also, for Demirdache \& Uribe-Etxebarria (2004), the perfective corresponds to an empty head in the Aspect node, whereby the Reference Time and the Event Time become the same. In this respect, my take is closer to the original one given in Klein (1994) and Klein et al (2000).

${ }^{5}$ In other works (e.g. Klein 1994, Kratzer 1998) the perfective is described as the viewpoint where the Event time is contained within the Assertion Time. The appealing of a table like the one above is that it allows us to establish the temporal relations under a uniform structural relation between intervals (e.g. Assertion Time always is in subject position to the predicate).

${ }^{6}$ Regarding the predicate of inclusion within, it seems that the most prototypical view of it is that one where the Assertion Interval is placed right in the middle of the Event Time interval. However, nothing restricts the inclusion relation in this respect. The Assertion interval can overlap any point of the event interval, i.e. a time towards the beginning, the middle or towards the end. That is, a sentence such as "John was writing a letter when Sue entered" can be used to describe a scenario where Sue entered the room when John was writing the final full stop of his letter. As long as the writing of the full stop counts as part of the writing of the letter, the sentence could be used to describe such a situation. In this sense, even a situation where the Assertion time overlaps the culmination point can be considered appropriately described by the inclusion predicate. I thank one of the reviewers for discussion in this respect.
} 


\section{The construction of progressiveness}

The literature about the progressive is vast and the accounts for its properties numerous and diverse. ${ }^{7}$ The aim of this section is not to discuss which account fares better but to establish the level of aspectuality where it belongs, in what sense it can be associated with imperfectivity and what meaning component shares with other aspr $\mathrm{ll}$ forms.

\subsection{The progressive and situation aspect}

The progressive is traditionally described as the form that yields the interpretation according to which the eventuality in question is understood as 'ongoing', as opposed to 'finished' or 'completed' (Comrie 1976). It has often been debated whether the progressive is imperfectivity (being a kind of viewpoint aspect) or atelicity (being related to situation aspect). In examples with predicates that qualify as telic in other structures (e.g. draw a castle in Marta drew a castle in ten minutes), the progressive has the interpretive consequence of non-asserting the culmination of the process. For example in (8), a castle had not been drawn; we do not know whether the event of "castle drawing" was ever instantiated. This would lead us to conclude that the progressive is a head bringing absence of culmination, a-telicity. This conclusion is supported by what has been pointed out on numerous occasions, namely, that whenever the progressive is involved, the predicate behaves similarly to atelic predicates in, for example, rejecting "in+time" modifiers. Examples in (9) show that a predicate such as "draw a castle"in the progressive behaves similarly to predicates that refer to situations that do not need to reach any specific point to be instantiated (e.g. swim).

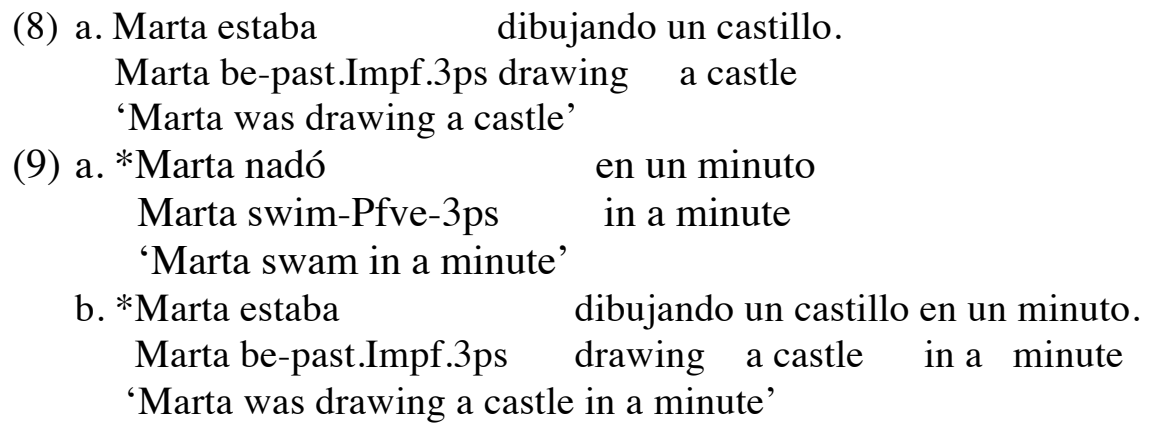

Given the parallel reaction with in-time modifiers, a tempting conclusion is that the progressive belongs to the computation of the eventuality type and its morphology is a signal for situation aspect. Within the syntactic approach to situation aspect adopted here (section 2), situation aspect is characterized as a result of the syntactic structure that the verbal root meets. To explain the atelic properties of telic predicates in the progressive, two logical possibilities, at least, come to mind: either the progressive is taken as the morphological expression of a head that encodes "atelicity", in complementary distribution to the projection that conveys telicity, or the progressive is an atelic head that co-exists with projections that give divisibility and telicity (e.g. projection of Quantity in Borer's 2005

\footnotetext{
${ }^{7}$ To name just a sample, some important works of reference are Dowty 1979, Parsons 1990; Landman 1992; Zucchi 1999; Higginbotham 2004.
} 
work) and destroys telicity. In what follows I show that neither of these options seem tenable. If the progressive were an atelicity head, it would be in complementary distribution with whatever head that makes a predicate telic (e.g. a Quantity head in Borer's 2005 account). If the progressive were understood in complementary distribution to the head conveying heterogeneity (instead of in addition to it), some fundamental facts regarding the difference between homogeneous and heterogeneous predicates would be lost, as all predicates in the progressive would become alike. For example, there would not be a way to explain the well-known contrast base of the imperfective paradox, as shown in (10).

a. Marta was swimming $\rightarrow$ Marta had swum

b. Marta was drawing a castle $\neg \rightarrow$ Marta had drawn a castle

The other idea, that of the progressive as a situation aspect head with the role of destroying telicity, has been put forward by authors such as Bertinetto (1994) or Borer (2005), among others. From their perspective, in the progressive, telicity is suspended; the progressive makes telic predicates undergo a sort of "detelicization" process. Borer (op. cit.), for example, argues that the progressive resembles negation; just as sentences involving negation are not a claim about a non-event but a claim that a given event did not take place, the role of the progressive is "to negate event's culmination if there is one" (Borer 2005: 236). However, it seems difficult to extend this view directly onto progressive clauses. A sentence in the progressive does not claim that an event did not culminate; it is not a negation of culmination. That the event did not culminate is, at most, an invited inference under certain discursive situations; context knowledge can block such an interpretation. Consider the following cases:

(11) When Matisse met Picasso, he was painting his self-portrait. Maria's first son was born when she was writing her thesis.

If we know about Picasso, we know that he culminated the painting; however, that does not make (11) anomalous. That is, (11) is perfectly compatible with the situation where Picasso finished his painting. If the hearer is familiar with Picasso's work, an interpretation where the painting is understood as nonculminated does not arise. Same thing in (12), if you are familiar with the Maria of the sentence and you know that she actually completed her thesis, the interpretation of non-culmination does not arise. If the hearer is not familiar with her, though, s/he has no foundation to draw any conclusion about whether she completed the thesis or not. The point is that the felicitous use of the progressive does not depend on the actual final culmination. The progressive just establishes a relationship between the intervals corresponding to the two events (i.e. meeting Picasso, painting the self portrait). What sentences like (11) or (12) claim is that Matisse meeting Picasso happened within an interval during which Picasso was engaged in the painting and the time when the child was born is included in the period that the writing of the thesis took. The fact that the progressive cannot be said to reverse culmination and affect the properties of the situation, but to contribute a specific relationship between two intervals suggests that the progressive is better analyzed as a viewpoint aspect element, rather than a situation aspect one. The conflict between telicity (understood as heterogeneous properties of the predicate) and progressivity, from this point of view, does not 
ensue. Heterogeneity is a property of those predicates whose parts are not alike and complies with the cumulative and divisibility properties shown in section 1 above. Since only heterogeneous predicates can culminate because their parts are different, telicity, or the reach of a significant point where the event instantiates is a property reserved to heterogeneous predicates. This does not mean that heterogeneity depends on completion, which is why heterogeneous predicates can appear in the progressive. With heterogeneous predicates in the progressive, a part of the event is understood as instantiated. It is not that the predicate becomes homogeneous; a part of it is understood as having occurred. Thus, there is no contradiction between being heterogeneous and being in the progressive, because being heterogeneous does not amount to being completed. ${ }^{8}$ If the progressive rendered heterogeneous homogeneous, homogeneous and heterogenous predicates would have equivalent interpretive consequences, but this was already discarded in (10). Additional evidence in the same spirit suggesting that heterogeneity coexists with the progressive comes from the fact that the combination of the progressive with heterogeneous predicates yields the interpretation of being halfway, which is not available with homogeneous predicates. This also points to the conclusion that it is not that the progressive destroys what has been built: heterogeneity, built by the Quantity projection, bringing divisibility, is still present. ${ }^{9}$ Taking stock on recent literature about degrees, I recycle some tests below. I use the one based on the acceptability of the adverbial gradualmente 'gradually', originally due to Piñón (2000), (13)-(15), and on the acceptance of $a$ medias 'halfway' (Kennedy \& Levin 2008, among others), (16)-(17). If these adverbials combine only with eventualities that can become telic (i.e. that are heterogeneous), the fact that it can still appear with the progressive, and that heterogeneous events can be referred back as being halfway can be taken as an indication that heterogeneity survives when the progressive is added on. ${ }^{10}$

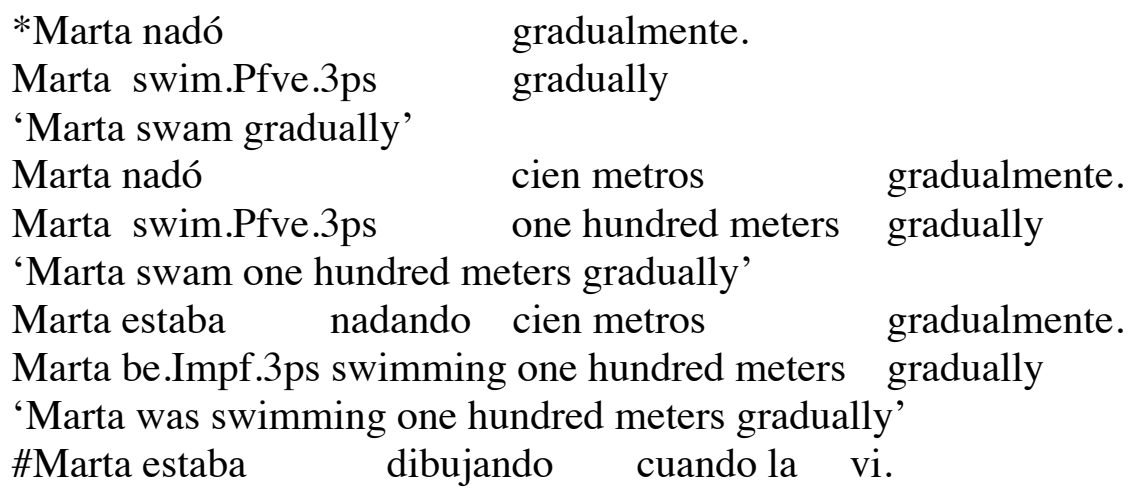

\footnotetext{
${ }^{8}$ At least, in the languages dealt with in this paper. A reviewer points out that the mechanism of de-telicization can occur in languages where the telic nature of the predicate is not formally expressed (e.g. Slavic languages). I leave the crosslinguistic analysis of this topic for future research.

${ }^{9}$ Garey (1957) said that the conception of telicity as a lexical aspect property was just an illusion; he claimed that it is perfectivity that makes culmination effective. As will be discussed later on in the section about continuity, although it is true that with events in the past it is only when heterogeneity and perfectivity co-occur that markers of telicity (e.g. in-time adverbials) are possible, such markers can combine with other viewpoint forms different from the perfective, such as the ones yielding capability readings e.g. Antonio writes a paper in one evening 'Antonio is able to write a paper in one evening'. More on this in section 4.

10 The object on (17) is feminine in Spanish to make it clear that the pronoun of the second sentence refers back to the event. As the contrast suggests, only the accomplishment gives a good result.
} 


Marta be.Impf.3ps drawing when her saw-1ps.
Lo dejó a medias.
it left.3ps halfway
'Marta was drawing when I saw her. She left it halfway'
Marta estaba dibujando una silla cuando la vi. Lo
Marta be.Impf.3ps drawing a-fem chair when her saw-1ps. it
dejó a medias.
left.3ps halfway
'Marta was drawing a chair when I saw her. She left it halfway'

\subsection{On the relation between progressivity and imperfectivity. Perfective progressives and non-culminating perfectives}

As mentioned above, the progressive makes the event be understood as 'ongoing', which has been classically associated with 'imperfectivity' (Comrie 1976). As a matter of fact, in many languages that exhibit an imperfective/perfective contrast in their tense-aspect inflection system, the progressive is an interpretation available with the imperfective. In Spanish, the progressive reading can be equally expressed by a periphrasis containing a copular verb and the main verb in present participle (18) and by an inflected imperfect form (19). ${ }^{11}$

$$
\begin{aligned}
& \text { Marta estaba dibujando un castillo (cuando la visité) } \\
& \text { Marta be-past.Impf.3ps drawing a castle (when I visited her) } \\
& \text { 'Marta was drawing a castle when I visited her' } \\
& \text { Marta dibujaba un castillo (cuando la visité). } \\
& \text { Marta draw-Impf.3ps a castle (when I visited her) } \\
& \text { 'Marta was drawing a castle when I visited her' }
\end{aligned}
$$

As the translations into English indicate, the interpretation of the two forms is the same. In both cases the subject is understood to be engaged in the process of drawing a castle when I visited her. For this reason, I assume that the inflected and the periphrastic forms are in free alternation and the semantic components involved in both forms can be reasonably argued to be identical. ${ }^{12}$ Imperfective inflection has been classically analyzed in opposition to the perfective, which is associated with the interpretation that the eventuality is finished (Comrie 1976). Unlike (18) and (19) above, with a sentence such as (20), with the perfective, the hearer is entitled to conclude that the subject completed the drawing of a castle.

$$
\begin{aligned}
& \text { Marta dibujó } \quad \text { un castillo. } \\
& \text { Marta draw-Pfve.3ps a castle } \\
& \text { 'Marta drew a castle' }
\end{aligned}
$$

\footnotetext{
${ }^{11}$ For ease of exposition and concreteness in the discussion that follows I will be adding a modifier (e.g. cuando la visité, 'when I visited her') to the AT.

${ }^{12}$ Some authors (e.g. Bonomi 1998) have argued that the analytical progressive is identical to the synthetic form only with activity predicates. A detailed analysis of these differences would take us too far afield here and I reckon that nothing major of what will be discussed here is affected by such differences.
} 
Thus, it is not surprising that (20), containing a heterogeneous predicate (an accomplishment), gives grammatical results in combination with the modifier taken as a reliable mark for telicity, in-time adverbials:

$$
\begin{aligned}
& \text { Marta dibujó un castillo en diez minutos. } \\
& \text { Marta draw-Pfve.3ps a castle in ten minutes } \\
& \text { 'Marta drew a castle in ten minutes' }
\end{aligned}
$$

What is puzzling is that the same sentence in the perfective gives equally grammatical results in combination with the adverbial commonly taken as a reliable mark for atelicity, i.e. for-adverbials (22). This combination is not unique to Spanish and is attested for other languages as well including English.

Paradigmatic examples in this regard are those coming from the literature of the so-called "degree achievements" (Dowty 1979) (23). As is well-known, such predicates combine equally well with for and in-time adverbials:

$$
\begin{aligned}
& \text { Marta dibujó un castillo durante diez minutos. } \\
& \text { Marta draw-Pfve.3ps a castle for ten minutes } \\
& \text { 'Marta drew a castle for ten minutes' } \\
& \text { Juan vació la piscina \{en/durante diez minutos\}. } \\
& \text { Juan empty-Pfve.3ps. the pool \{in/for ten minutes\} } \\
& \text { 'John emptied the pool }\{\text { in/for ten minutes }\} \text { ' }
\end{aligned}
$$

The interesting point of such sentences, which contain a perfective, is that culmination can be cancelled. Consider the possible continuations for (22), where assertion of lack of culmination does not produce an infelicitous utterance.

$$
\begin{array}{lll}
\text { Marta dibujó } & \text { un castillo } & \text { durante diez minutos, pero } \\
\text { Marta draw-Pfve.3ps a castle } & \text { for ten minutes, but }
\end{array}
$$

no lo terminó.

not it finish-Pfve.3ps.

'Marta drew a castle for ten minutes but she did not finish it'

Although a full examination of these cases would take me too far afield in this work, in what follows I provide the main lines of an account for non-culminating accomplishments in Spanish, paying attention to the predicate type and the role of modifier adverbials such as durante $x$ 'for-time'. The account I explore here is that absence vs. presence of completion in Spanish derives from a different syntax-semantics of the perfective viewpoint. When a perfective can be understood with absence of completion, it can be paraphrased by what can be called a "perfective progressive": an analytical form with the auxiliary in the perfective followed by the present participle of the verb at hand, as observed in the glossed below:

$$
\begin{aligned}
& \text { Marta estuvo dibujando un castillo (durante diez } \\
& \text { Marta be-Pfve.3ps drawing a castle (for ten } \\
& \text { minutos), pero no lo terminó. } \\
& \text { minutes), but not it finish-Pfve.3ps } \\
& \text { 'Marta was drawing a castle (for ten minutes) but she did not finish }
\end{aligned}
$$$$
\text { it' }
$$ 
This shows that, just as the imperfective, the perfective inflectional form can be associated with more than one meaning (more than one syntax-semantics). Perfective progressives show that progressivity is not associated with imperfective marking only. The interpretation as perfective progressive of perfectives in Spanish suggests that perfective forms may be internally complex, susceptible to being deconstructed. Their study adds to the growing body of literature that has been uncovering cases of heterogeneous eventualities in the perfective that can be interpreted as non-culminating, in a variety of unrelated languages including Chinese (Smith 1991, Koening \& Chief 2008), Hindi (Singh 1998), Lilloet and Squamish Salish languages (Bar-el, Davis and Matthewson 2005), Thai (Koening and Muansuwan 2000), Karachay-Balkar (Tatevosov 2008), Russian (Altshuler, this issue), among others. The main question of all these studies concerns the source of completion and lack thereof. Most of these analyses locate it in the stems of the verbal predicates in different ways. For Bar-el, Davis and Matthewson (op. cit.), Salishan accomplishments are telic roots whose requirement of completion in the actual world can be removed from the bare root in the syntax by a control transitivizer. Koening and Muansuwan (op. cit.) and Tatevosov (op. cit.) argue for Thai and Karachay-Balkar that accomplishments stems contain an imperfective and a maximal operator that bias the predicate towards imperfectivity. Although all these works make use of tools and constructs that belong to the imperfective in the literature (e.g. notice the use of an imperfective operator by Koening \& Muansuwan 2000 and Tatevosov 2008 or the idea that the control transitivizer in Salish introduces inertia worlds in Bar-el, Davis \& Matthewson 2005), they all clearly establish that the perfectives at hand cannot be mistaken by imperfectives. Using the vocabulary of the present work, we can say that the interpretation of the relation between the intervals is not the one that the imperfective establishes. The AT of the perfective sentences clauses cannot be modified in the typical way imperfectives are, for example by a whenclause like in She was baking a cake when I saw her. The analysis of incomplete accomplishments that I will sketch here for Spanish has two main features: (i) it situates completion or lack thereof clearly within the realm of viewpoint aspect; in general, a perfective yields an incomplete accomplishment reading when it can be paraphrased by a perfective progressive. I take this to be suggestive of different underlying viewpoint aspect semantics. (ii) It identifies the component of the imperfective responsible for yielding the incomplete reading as a subpart of what is generally known as progressive. Thus, the account introduced here does not face the issue of proposing elements that belong to viewpoint aspect but operate within the verbal stems at a much earlier point of the derivation as happens in the aforementioned accounts (e.g. Koening \& Muansuwan 2000 themselves admit this to be problematic in their account).

The lack of culmination reading with accomplishments in the perfective preterit observed in Spanish in cases such as (24) above is a reading where partial success is obtained. In (24) the subject has partially drawn a castle. However, unlike what seems to be the case in other languages, ${ }^{13}$ the non-culminating reading with the perfective arises much more easily (and for some speakers uniquely) when an adverbial restricts the duration of the interval the eventuality occupies. That is, only when adverbials such as, for example, durante $x$ 'for time' or de $x$ to

\footnotetext{
${ }^{13}$ Koening and Muansuwan (2000) give the equivalent to for-time adverbials as excluded with Thai non-completive perfectives. If this is so, then the account needed for Thai is different from the one offered here.
} 
$y$, 'from $\mathrm{x}$ to $\mathrm{y}$ ' are in place. Otherwise, assertion of lack of culmination produces contradictory sentences for most speakers:

\#Marta dibujó $\quad$ un castillo, pero no lo terminó.

Marta draw-Pfve.3ps a castle, but not it finish-Pfve.3ps.

'Marta drew a castle, but she did not finish it'

\#Ayer arreglé la valla, pero no terminé.

Yesterday fix-Pfve.1ps the fence, but not finish-Pfve.1ps.

'Yesterday I fixed the fence, but I did not finish. I have to continue today'.

As shown in (25), if a durative adverbial is in place, assertion of lack of culmination is felicitous. In such cases, the perfective can always be paraphrased by a perfective progressive. When a perfective progressive form is explicit an adverbial restricting duration is not necessary to draw the lack of completion reading:

$$
\begin{aligned}
& \text { Marta estuvo dibujando un castillo, pero no lo terminó. } \\
& \text { Marta be-Pfve.3ps drawing a castle, but not it finish- } \\
& \text { Pfve.3ps. } \\
& \text { 'Marta was drawing a castle but she did not finish it' } \\
& \text { Ayer estuve arreglando la valla, pero no terminé. } \\
& \text { Yesterday be-Pfve.3ps fixing the fence, but not finish- } \\
& \text { Pfve.1ps } \\
& \text { 'Yesterday I was fixing the fence but I did not finish' }
\end{aligned}
$$

That is, the perfective progressive is always compatible with restrictive durational adverbials but does not need them to produce the partial success or nonculminating reading. It could be argued that what these temporal adverbials do is to impede telicity from ensuing (e.g. Borer 2005 attributes anti-telicity effects to for-time adverbials). However, if that were the case, an interpretation where culmination is asserted would be excluded, contrary to the fact. That is, if for-time adverbials were a signal or a tool to create atelic syntactic contexts, culmination would never be a possibility. However, it is. All the cases above, with the perfective preterit and the perfective progressive, can be used to describe a situation where culmination obtains:

(31) Marta dibujó/estuvo dibujando un castillo durante dos horas, y lo terminó.

Marta draw-Pfve.3ps/ be-Pfve.3ps drawing a castle for two hours, and it finish-pfve. 3 ps

'Marta drew/was drawing a castle for two hours and she finished it.'

Ayer arreglé/ estuve arreglando la valla durante dos horas y terminé.

Yesterday fix-Pfve.1ps/be-pfve.3ps fixing the fence, and finishPfve.1ps.

'Yesterday I fixed/was fixing the fence for two hours and I finished'

I conclude that, at least in Spanish, we do not want to embed the source of culmination into the syntax, as we need to leave room for both culmination and lack thereof as possibilities. This fact raises questions about the relation between 
the perfective progressive and the perfective preterit, between the progressive and the culminating reading and between the perfective and both the culminating and non-culminating readings. Based on the interpretive equivalence shown between the perfective preterit and the perfective progressive (i.e. the perfective can be paraphrased by a perfective progressive), I argue that the perfective preterit can have a syntax-semantics equivalent to the perfective progressive. That is, that the perfective preterit form can correspond to more than one syntax-semantics. The specifics of this are detailed in the next section. Regarding the relation between a progressive component and culmination, perfective progressives highlight again the difference between being divisible (i.e. heterogeneous) and culminating. The culmination reading emerges with the perfective preterit in the presence of modifiers restricting the AT, as discussed. The role that the for-time adverbial plays in yielding the lack of culmination reading suggests that the culminated interpretation in Marta dibujó un castillo 'Marta drew a castle' may be an implicature emerging from assuming that the information provided is the maximum amount of information relevant (Grice 1975). ${ }^{14}$ That is, since no adverbial restricting the AT interval is provided, the event is understood as completed. When the assertion is made for a limited amount of time as in Marta dibujó un castillo durante dos horas 'Marta drew a castle for two hours', assuming that the adverbial provides us with the maximum amount of information needed, the interpretation that she was drawing only for two hours emerges by implicature again. However, from a truth-conditional point of view, the sentence would still be true if Marta had been drawing from 1 to 5 . The fact that adverbials compatible with perfective progressives (e.g. for-time adverbials) combine with the perfective preterit suggests that the underlying syntax-semantics allows for it; in particular, that a structure that does not give rise to completion (telicity) is in place. Here I suggest that it is a progressive structure. As mentioned before, it produces the interpretation that part of the situation has taken place. If the complement is a quantified DP, the reading that emerges is that where the action was started in all of them. For example in (33) Marta started drawing three castles, probably she drew a bit of one, then she moved on and drew a bit of the other one and then a bit of the third one. There are three instantiations of castle drawing started and the drawing overlaps and coincides with the interval of time described by the AT. The sort of modifiers allowed marks the difference between the perfective progressive and the imperfective progressive (the latter being what is commonly known as imperfective or as progressive alone). Adverbials measuring the duration of the whole interval the eventuality is asserted to extend over are excluded when some form of the imperfective is involved, in the auxiliary of the analytical progressive or in the inflected imperfective (34), as has been noted by other authors (e.g. Menéndez-Benito 2000).

Marta estuvo dibujando tres castillos durante dos horas. Marta be-Pfve.3ps drawing three castles for two hours horas.

$$
\text { * Marta estaba dibujando/ dibujaba un castillo durante dos }
$$

Marta be-Impf.3ps drawing / draw-Impf.3ps a castle for two hours

\footnotetext{
${ }^{14}$ I want to thank Hamida Demirdache for discussion around this issue.
} 
This seems to suggest that the relation between the AT and the EvT is different in each case, depending on the aspectual form of the auxiliary. While with the imperfective, the AT is included, or contained, in the EvT, with the perfective progressive the AT seems to totally overlap the EvT, which crucially makes it possible to include the initial and final boundaries of the EvT, which is why the interpretation where the castles were finished becomes available. With perfective progressives the event is presented in its progression and the span of time it is asserted to take is understood as finished. In this sense, durante 'for-time' phrases are understood as modifiers of viewpoint aspect in so far as they measure the duration of the asserted interval. Strictly speaking, then, they are not banned from heterogenous contexts; whenever such adverbials are present, a nonculminating reading becomes available. This raises one question, though. If it is the whole EvT that is considered with the perfective, how is it that we can say at the same time that it is possible that the event itself can occupy a longer interval? Recall that we said that saying that Marta dibujó un castillo duran te 2 horas 'Marta drew a castle for two hours' is logically compatible with Marta drawing the castle for four hours. Following a Klinean way of reasoning we could say that the EvT is never really taken into account as the sentence concerns only the AT. I am not certain whether this is a fully satisfactory answer, since we cannot deny that the EvT plays a crucial role in yielding the aspectual interpretations, since it is considered to be one element of the ordering. That is, up to at least a certain extent, the EvT is relevant and should be visible for the interpretation of the sentence. If the actual EvT is not relevant, the logical compatibility between drawing a castle for two hours and drawing a castle for four hours in the actual world, is explained, but a question arises regarding the difference between the imperfect and the perfective. With the imperfective the AT is ordered within the EvT; with the perfective the AT was said to overlap the whole EvT, that is how completion was derived. However, if the overlap does not have to be "total", but as much as asserted by the AT, the difference between inclusion and overlap blurs. This suggests that the content of the predicate of the perfective needs further research. ${ }^{15}$

Thus far, I have worked with accomplishments because they provide us with the grounding test to discuss the relation between culmination and the perfective. Not surprisingly, the perfective can also be paraphrased by a perfective progressive with activity-type predicates:

$$
\begin{aligned}
& \text { Marta nadó/ estuvo nadando (durante dos horas). } \\
& \text { Marta swim-Pfve.3ps/ be-Pfve.3ps swimming (for two hours) }
\end{aligned}
$$

Conversely, lack of culmination is a reading virtually absent with achievements (36). This follows naturally if we relate lack of culmination to an underlying progressive aspectual predicate. ${ }^{16}$ The difficulties of achievements to appear in the progressive are well-known; the lack of duration proper of achievements makes it very difficult to refer to their internal parts (37) or measure their duration (38). Correspondingly, their perfective preterits are not a paraphrase to a perfective progressive.

$$
\text { \#Marta encontró la aguja, pero no terminó de encontrarla. }
$$

\footnotetext{
15 I thank Tim Stowell and an anonymous reviewer for bringing this issue to my attention. 16 Tatevosov (2008) makes a suggestion along similar lines within a different approach.
} 


\begin{abstract}
'Marta found the needle, but she did not finish finding it'
* Marta estaba encontrando la aguja cuando entré.

'Marta was finding the needle when I entered'

* Marta estuvo encontrando la aguja (durante dos horas).

'Marta was finding the needle (for two hours)'
\end{abstract}

Non-culminating achievements appear to be very rare in all languages and subject to significant variability of judgments across speakers even in those where they have been claimed to be attested. ${ }^{17,18}$ The resistance of achievements to produce non-culminating readings is congruent with the proposal that a semantic component that is found within progressives is involved in the syntax that yields such readings.

To summarise. In this section I have shown that progressivity is not associated with imperfective marking only. I have shown that perfective progressives are a possible paraphrase to perfective preterits, which I have taken as an indication of a possible underlying semantics. I have argued that such progressive structure accounts for the perfective preterit of accomplishments with a lack of culmination reading. I have argued that the lack of culmination reading is not rooted in the verbal stems; in accordance with the agenda of the present work, just as culmination is not in the verbal roots but conceived as a possible interpretative consequence when heterogeneity is encoded in a functional head, absence of culmination is not conceived to be in the roots either. In this sense, the current proposal for Spanish differs in spirit from other accounts such as the ones recently proposed for Thai by Koening and Muansuwan (2000) and for Karachay-Balkar by Tatevosov (2008). I have also suggested that the culmination reading of perfective preterits emerges as an implicature in the absence of temporal modifiers restricting the interval the assertion applies for.

The analysis of perfective progressive forms, which have attracted little attention in previous literature (with some exceptional mentions, e.g. de Swart 1998, Bertinetto 2000) present an interesting case for the syntax of aspect, since they call for a separate analysis of the auxiliary and the present participle. Although it has been common practice to propose only one Aspect head for progressives in all frameworks (e.g. Demirdache \& Uribe-Etxebarria 2000 and subsequent work within the Klinean tradition), given that the auxiliary itself carries aspect, the structure of Aspect heads need to be revised. Perfective progressives are a case that allows us to disentangle the properties of the auxiliary and the present participle in the interpretation of the progressive. In the next section I present a revised syntactic structure for the progressive that allows us to

\footnotetext{
${ }^{17}$ Koening and Chief (2008) report that native speakers of Hindi differ significantly about the judgments they give for sentences containing verbs meaning 'kill', although they have commonly been used in studies about lack of completion.

18 However, it is interesting to note that, even those where the non-culminating reading is very limited, achievements still return an interpretation in the Spanish perfective progressive. It is what Tatevosov (2008) calls "failed attempt reading". Sentences such as (i) return an interpretation along the lines of (ii):
}

hora.

(i) Pedro estuvo descifrando el jeroglífico/abriendo la caja fuerte durante una Pedro be-pfve.3ps deciphering the hieroglyph/opening the security box for an hour

(ii) 'Pedro estuvo intentando descifrar el jeroglífico/ abrir la caja fuerte durante una hora' 'Pedro tried to decipher the hieroglyph/open the security box for an hour' 
capture both the imperfective and perfective progressive forms and to account for non-culminating readings with accomplishments.

\subsection{The Morpho-syntax of the progressive}

In the previous subsections I have argued that the progressive is a form that belongs to the realm of viewpoint aspect and that it can be expressed by different morphological forms (imperfect and preterit, analytical and synthetic). In this section I give a proposal regarding the morpho-syntactic structure of the progressive. In order to capture the complex aspectual semantics described above, which is directly observable in the analytic forms of the progressive, where the auxiliary copular verbs are shown to be inflected for aspect, I propose that there is more than one head involved. The upper Aspect head, morphologically expressed by the auxiliary verb in analytical forms, hosts a predicate of temporal ordering either with the meaning of within (imperfective) or with a meaning such as over, total coincidence (perfective); the lower head morphologically expressed by the present participle ending of the lexical verb (Spanish V-ndo; English V-ing) has the content of an ordering predicate meaning within. I argue that the lower head of the structure is in charge of accessing parts of the eventualities, which makes the preterit able to truthfully describe a situation where culmination is lacking. Thus, since we have two ordering predicates, the number of intervals involved in the interpretation must be three.

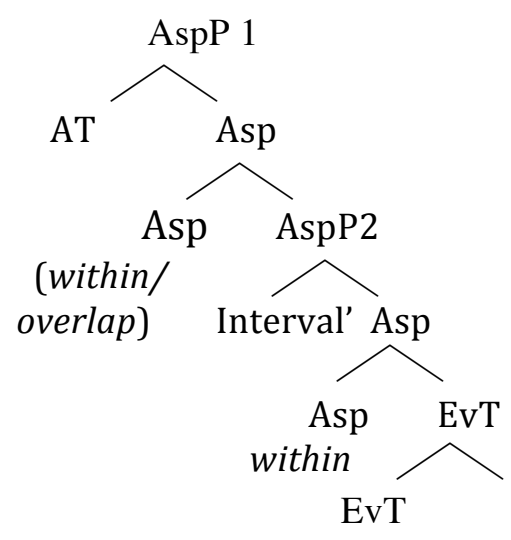

This structure suggests that two relationships are established: on the one hand, the aspectual predicate expressed by the inflected auxiliary establishes a relationship between the AT (e.g. the one modified by when I visited her in our examples) and another interval. This relationship can be of different sorts, including total overlap (when Asp1 is perfective) or inclusion (when Asp1 is imperfective). The latter interval is related to the Event Time by the second aspect head, which manifests itself as a present participle form morphologically and has inclusion as its semantic component. With the auxiliary in the imperfect, the visit time (AT) is included within an interval that falls within the interval of drawing; with the auxiliary in the perfective, the AT totally overlaps with an interval that falls within the interval over which the event of drawing extends. This analysis allows us to capture the two cases with the desired interpretations. In a sentence with a Perfective progressive (Marta estuvo dibujando un castillo cuando la visité 'Marta was-Pfve drawing a castle when I visited her') the structure in (39) reads the following way: the AT (when I visited her) overlaps with an interval that is 
located within the interval of the event of drawing. That is, the interval that overlaps with the AT is in itself contained in the (arguably larger) event time. This complex relation explains that the AT is finished and, at the same time, that the event may not have culminated. For uniformity, with a sentence with an Imperfect progressive (Marta estaba dibujando un castillo cuando la visité, 'Marta wasImpf.3ps drawing a castle when I visited her') the structure is proposed to be the same, and it would read: the AT (when I visited her) is contained within an interval that is contained in the Event Time. ${ }^{19}$

The subsequent issue that needs attention is the morphological account of the (synthetic) Imperfect inflected form with a progressive reading. I argue that in this case the lower head is phonetically empty and the inflection representing Tense and Aspect content is carried by the lexical verb itself. The structures corresponding to the two forms (analytical and inflectional) are below:

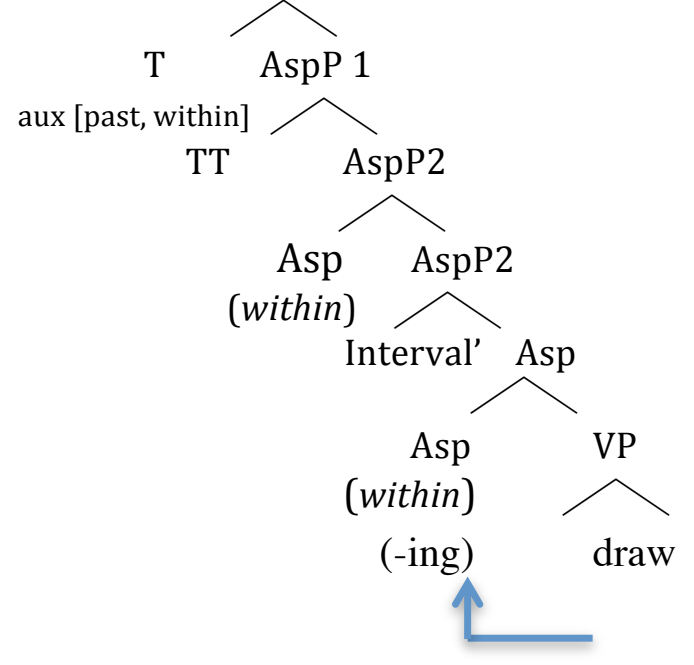

b.

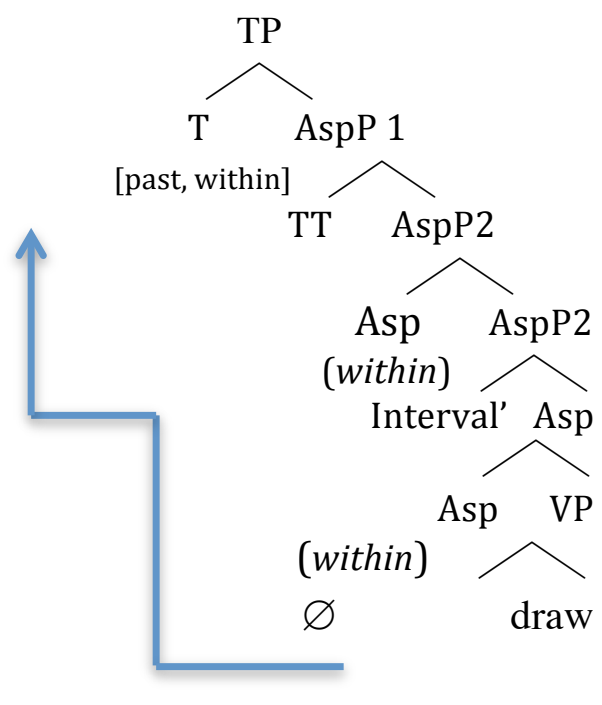

The structure of (40a) yields the analytical form "estaba dibujando" (wasImpf.3ps drawing); the structure in (40b) gives the inflected Imperfect "dibujaba" (draw-Impf.3ps). In the former it is the auxiliary verb that carries the bundle of tense and upper aspect morphemes; in the latter it is the lexical verb itself that carries all the information but, crucially, the syntactic structure involving two aspect heads is the same.

Likewise, perfective progressives can come in two forms: synthetic and analytical. In the same spirit as above, the structures proposed for the analytical form of perfective progressive and the non-analytical form are the ones below.

\footnotetext{
${ }^{19}$ While in perfective progressives the Aspect heads contain different semantic content each, in the latter it is not the case, raising the question of vacuous viewpoint shifting. Demirdache \& Uribe-Etxebarria (2000) argue that when Aspect does not focus a time interval that is distinct from the first aspect the result is anomalous (*Rosa is being reading). However, this does not explain why Rosa is reading, where the inflected and non-personal form can be argued to have the same semantic component underlying, is fine.
} 


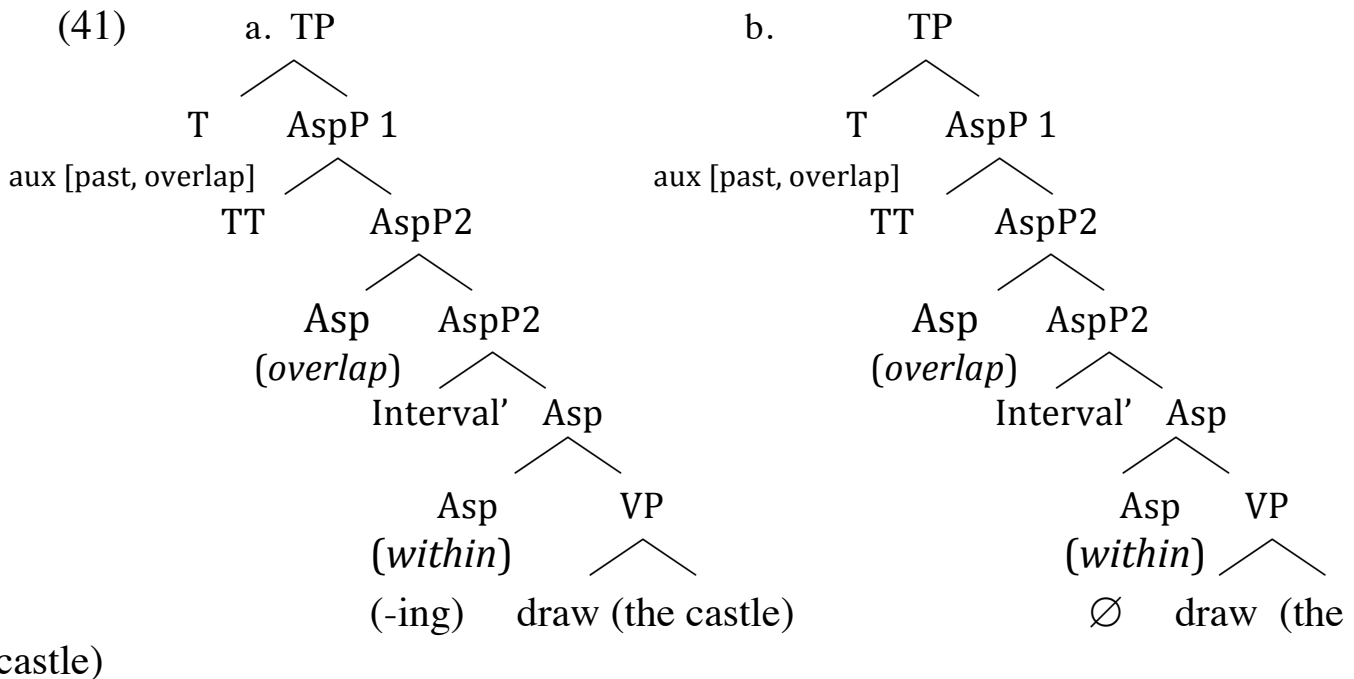

The structures in (41) both represent what I have called "perfective progressives". Different external morphology may have the same semantics in the syntax. In (41a) the auxiliary carries the inflectional morphemes corresponding to the Tense and Aspect blend (past, perfective) and the lexical verb carries the present participle form. In (41b) it is the lexical verb that carries the inflectional morphemes corresponding to the Tense and Aspect bundle but the syntactic presence of a lower aspect head triggers the progressive interpretation. As said above, these data reveal that the progressive is not necessarily tied to Imperfect marking. ${ }^{20}$

\section{The construction of the continuity}

The idea that the progressive does not combine with states is very often found in the literature. As a matter of fact, the appropriateness of the progressive has been traditionally used as a tool to diagnose whether a given predicate should be considered as a state or not (Lackoff 1966, Dowty 1979). Thus, in general, when scholars refer to the reading that ensues with states but does not have a habitual interpretation and is not paraphraseable by an analytical progressive form, they use the label "continuous". In this section I will study the semantics and syntax of this reading and I will discuss the kind of predicates it occurs with as well as its differentiation from the progressive.

\subsection{The semantics of continuity}

In essence, the classical description of the continuous interpretation is very similar to the one offered for the progressive reading: the AT is understood as included within the interval over which an eventuality holds. The reason why it has been

\footnotetext{
${ }^{20}$ It is conceivable to extend this view to all auxiliaries, including those involved in the construction of the perfect tenses. The auxiliary "haber" 'have' is inflected for tense and aspect in Spanish morphologically; the pluperfect contains an imperfective form (había dibujado), different from the so-called anterior preterit, which involves the auxiliary in the perfective (hube dibujado). The occurrence and distribution of the anterior preterit is admittedly limited in modern Spanish but it clearly contrasts with the pluperfect in ways that need to be defined in future research.
} 
usually considered separately (e.g. Bogaart 1999, Deo 2009, García Fernández 1999 for Spanish) is that authors want to underscore the difference between the predicates that can appear in the progressive analytical form, which are considered dynamic (e.g. activities, accomplishments), versus other kinds of predicates that do not combine with it as naturally: states. Whether the distinction between progressive and continuous is supported by a substantial difference in the content of the viewpoint heads, or these two readings can be considered to be alike, the only difference being the VP-predicate they combine with, is the topic of the following discussion. The example below is of the kind typically employed to describe the continuous reading.

$\begin{array}{lll}\text { Juan estaba } & \text { enfermo } & \text { cuando llegó a casa. } \\ \text { Juan be-Impf.3ps } & \text { ill } & \text { when he got home } \\ \text { 'Juan was ill when he got home' } & \end{array}$

The interpretation of (42) is that the AT (included in cuando llegó a casa 'when he got home ${ }^{21}$ ) is located "within" the time of Juan's being ill. ${ }^{22}$ To be able to figure out whether the continuous reading has exactly the same semantics and syntax than the progressive (the only difference coming from the predicate they combine with, state vs. dynamic), or whether they are different creatures, I will work with minimal pairs consisting of state verbs in synthetic imperfect and in the progressive analytical form. I am going to focus on state predicates whose reading in the progressive is as natural as in the non-progressive form, to steer the discussion away from borderline interpretations. If the meaning is different, we can conclude that the structure of the so-called continuous reading must be different from that of progressive reading. Consider the following contrasts. pareció cara.

$$
\text { a. Me encantaba la película, pero no la compré porque me }
$$

me love-Impf.3ps the movie, but not it buy because me seemed expensive.

\footnotetext{
${ }^{21}$ As before, I will use when-clauses to modify the AT and make the discussion easier to follow.

${ }^{22}$ A reviewer asks how the aspectual approach adopted here, where the imperfective is understood as 'within' could account for sentences such as La catedral era alta y larga 'The cathedral wasimpf tall and long', given that the cathedral possesses such properties during its whole existence. This example regards the temporal interpretation of Individual-Level predicates. Recall that, as described in section 2, in the model adopted here, what Tense and Aspect locate in time (Klein 1994 and subsequent work) is not the eventuality (in this case the properties described by the predicate) but an interval, namely, the assertion time or topic time. With Individual-Level predicates the Assertion Time can be either the one corresponding to a salient interval in the discourse (i) or to the one corresponding to the whole lifetime of the referent, which leads to lifetime effects. This perspective allows us to account for both the emergence and the blocking of lifetime effects, among other issues (see Klein 1994, Musan 1997 and Arche 2006 for details). Importantly, in both cases the Assertion Time (whatever its reference is) is always included within the Event Time (the whole span of time the eventuality occupies --likely coinciding with the lifetime of the cathedral), which is compatible with the semantics for the imperfect proposed in the paper.

(i) Visitamos Burgos el verano pasado para ver sus monumentos. La cathedral era alta y larga y el paseo principal ancho y arbolado.

We visited Burgos last summer to see its monuments. The cathedral was-impf tall and long and the main avenue wide and full of trees.

(ii) La catedral era alta y larga. Ya no hay nada por culpa de los bombardeos del 39. The cathedral was tall and long. There is nothing left due to the bombing of the 39.
} 
'I loved the movie but I did not buy it because it seemed expensive to me'

b. Me estaba encantando la película, pero decidí irme a me be-Impf.3ps loving the movie, but decided-I go to dormir para descansar bien. sleep to rest well rest'

'I was loving the movie, but I decided to go to bed to have a good cara.

a. Me encantaba la mesa, pero no la compré porque me pareció

me love-Impf.3ps the table, but I did not buy it because it seemed expensive to me.

'I loved the table but I did not buy it because it seemed expensive to me'

b. \#Me estaba encantando la mesa, pero no la compré porque me me be-Impfve.3ps loving the table, but I did not buy it because

me

pareció cara.

it seemed expensive

'I was loving the table but I did not buy it because it seemed expensive to me.'

Examples (43) and (44) have the state predicate "love" and present well-formed sentences in the synthetic form. While with the analytical progressive form (43b) is completely natural, but (44b) is slightly odd. From a very superficial point of view, the difference between these two cases is in the objects that form part of the VP: "a movie" vs. "a table". The predicate like a movie has properties that make it similar to activities, such as the fact that it looks like an event that unfolds in time; it could be said that the event unfolds as the movie does, but what exactly the progressive brings into the picture when it combines with states still needs to be identified. Different authors have pointed out that the progressive brings "connotations of volition" (sic in Smith 1991) and dynamism to constructions (e.g. Smith 1991, Dowty 1979, Partee 1977). Why these two properties should be connected and how this contribution should be formalized is unclear yet. Firstly, it is not obvious why volition should be connected to viewpoint aspectual properties directly. For example, dynamic predicates can have animate and inanimate subjects, the latter being devoid of volition by definition (45), which weakens any association between progressivity and volition.

The leaf was falling from the tree

Furthermore, putting a predicate in the progressive does not make it automatically volitional. As observed in (46), the mere construction in the progressive does not make volitional adverbials compatible with the construction. This means that the progressive, as a viewpoint predicate, does not affect the eventive and argument structure of the predicate.

*Me estaba encantando la película a propósito me was-past.Impf.3ps loving 
These examples suggest that the progressive should be kept separate from the continuous since the progressive brings about a different interpretation from the non-progressive form with states. ${ }^{23}$ In the next section a proposal about the syntax and semantics of the continuous viewpoint is presented and its differences with the progressive are made explicit.

Although the progressive does not fare equally well with all states, the possibility of their combination cannot be denied. Given their licit combination in general lines and the reliance of the literature in the progressive as a test for eventivity, some authors such as Kearns (1991) have concluded that states as such do not exist. In this paper, the conclusion is that viewpoint aspect is not precluded, in principle, from co-occurring with any event type and that, when they do, event properties are preserved.

\subsection{The syntax of continuity}

I propose that the continuous and the progressive readings emerge from a different syntax. The continuous interpretation derives from a simpler structure than the one proposed above for the progressive. When the structure contains a complex structure with more than one ordering head and one more interval (47a), the progressive interpretation obtains (e.g. Me estaba gustando la película 'I was liking the movie'); when it has only one aspectual ordering head (47b), the socalled continuous interpretation is yielded (e.g. Me gustaba la película pero... 'I liked-imp the movie but....' )

a. TP

$\mathrm{T}$<smiles>CC[AsH2]</smiles>

aux [past, within]

AT

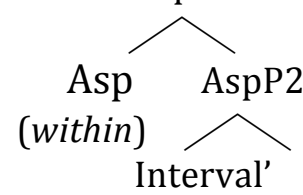

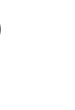$$
\text { (n) }
$$ 
I propose that it is the extra interval present in the structure of the progressive that makes the predicate be understood as unfolding in time; this extra interval produces the effect of development in time, provides the dynamicity effect. This way of looking at facts suggests that the state keeps being a state. As was seen, just by being in the progressive the rest of properties associated to eventiveness (e.g. agent oriented modification) do not emerge. The result is a state that holds at a (further) selected subinterval. When this is plausible, such as for instance due to the properties of the object, the sentence is completely natural; when the object does not help the VP to be understood as an event that unfolds in time other interpretations may emerge, such as inchoative (I was liking the table 'I was starting to like the table, but I noticed a flaw and changed my mind'). I argue that interpretations such as these emerge as a product of contrasts between intervals, which is possible after having introduced another interval in the structure. Klein (1994) argued that the progressive does not combine with states because there is no informative contrast between intervals: all are alike. From the approach argued for in here the perspective is that if another interval is introduced by the structure, a contrast between them becomes available as an interpretive consequence. Crucially, the progressive is not seen here as a coercive tool that empties states of their stativeness and turns them into dynamic processes.

I argue that, contrary to widespread opinion, the continuous structure is not unique to states, but eventive predicates can occur in it. I argue that, when this happens, it is the reading known as "ability", "characterizing" or "attitudinal" that emerges. The ability or characterizing reading is that reading according to which a certain ability is ascribed to an individual, independently from the actual instantiation of the event described by the predicate. In the absence of context or adverbials sentences can be said to be ambiguous between an ability and a habitual reading, which has also been described as characterizing (Schubert and Pelletier 1989, Bertinetto 1994, Krifka et al. 1995). There are differences between the two, as will be shown. The sentences below are examples ${ }^{24}$.

Juan lee francés/ escribe a máquina.

\footnotetext{
${ }^{24}$ I have discussed the ability reading using examples in present tense following previous practice in the literature to steer the discussion clear of additional interpretive effects that emerge in the past such as the so-called lifetime effects. I argue that no difference except for temporal reference derives from this and that the same conclusions can be applied to past imperfect. That is, the present and past imperfect are alike aspectually. The versions below in past imperfect would be the corresponding present in the past. Lifetime effects are those interpretative effects according to which the referent of the DP subject of a predicate in the past is understood as dead, if animate, or broken, if inanimate. In the examples below it is possible to understand that the printer is either broken or non-existent, and Marta and Pedro are non-alive. For more details about lifetime-effects see Kratzer 1995, Musan 1997, Arche 2006.
}

(i) Ese modelo imprimía 100 páginas por minuto

That model print-past.impf.3ps 100 pages per minute

'That model printed 100 pages per minute'

(ii) Marta repartía

los paquetes grandes.

Marta deliver-past.impf.3ps

the parcels big

'Marta delivered the big parcels'

(iii) Pedro escribía a máquina.

Pedro type-past.impf.3ps

'Pedro typed' 


\section{Juan reads French/ types}

These sentences have two readings: habitual, as is paraphrased in (49) and another reading where a habitual quantifier is not involved in the paraphrase of the interpretation (50), but a verb referring to ability.

(49) Juan lee francés/ escribe a máquina normalmente Juan reads French/types usually

$$
\begin{aligned}
& \text { Juan sabe leer francés/ escribir a máquina } \\
& \text { Juan knows how to read French/ how to type }
\end{aligned}
$$

The fact that explicit negation of habituality is not incompatible with the assertion of the ability proves that the ability reading does not derive from habituality:

(51) Juan lee francés pero no lo hace nunca; es un vago y siempre hace que alguien le traduzca las cosas.

'Juan reads French but never does it; he is very lazy and always has everything translated'.

Juan escribe a máquina, pero no escribe normalmente.

'Juan types but he does not type usually'

That is, these sentences do not mean that the subjects perform the actions expressed by their predicates on a regular basis. No interpretation arises that a particular set of occasions in which the event has taken place has held. It seems clear, then, that the characterization reading does not emerge from the fact that someone has performed the action in question often as some authors have suggested (Zemach 1975, Carlson 1977). The characterization reading does not derive from the habitual and is not just a possible reading from it.

Another contrast between the ability and the habitual reading pointed out in the literature (Bertinetto 1994) is that ability sentences do not support agentoriented modification. When it is present, the ability reading seems to disappear.

$$
\begin{aligned}
& \text { Juan escribe a máquina a propósito. } \\
& \text { 'Juan types on purpose' }
\end{aligned}
$$

For this reason authors such as Bertinetto (1994), among others, have argued that behind the ability interpretation there is an operation that deeventivizes the predicate; similarly Lenci (1995) proposes a stative structure that is superimposed onto the eventive structure. I am going to argue that the eventtype stays the same and there is no de-eventivization. Failure to support agentoriented modifiers is an indication of absence of agentive functional structure but not absence of eventive (non-stative) structure. Only non-states can be agentive, but not all eventive structures must be agentive. As is known, eventive nonagentive structures are possible:

(54) Una idea circuló por su cabeza durante años (*voluntariamente). An idea wandered around her head for years (*voluntarily) 
As a matter of fact, other modifiers indicating eventivity, such as telicity modifiers, can appear in ability sentences. Consider the following:

$$
\begin{array}{lll}
\text { Esa maquina aplasta } & \text { cien uvas } & \text { en diez minutos. } \\
\text { That machine crushes } & \text { a hundred grapes } & \text { in ten minutes }
\end{array}
$$

The sentence means that the machine has the ability to perform an event of crushing a hundred grapes within the span of time of ten minutes. To the extent that the in-time adverbial can be considered as a mark of telicity, it can be considered that there is an underlying event structure. That is, we can consider that the underlying event structure is actually eventive, and non-stative, despite the ability reading. In other words, eventiveness has not disappeared after the merge of the viewpoint (continuous) head.

Following Verkuyl (1999), Ferreira (2005) and Arche (2006), I consider that the syntax of the progressive includes a quantifier over occasions by virtue of which reference is made to one instantiation of an event. In a similar vein, as will be shown in next section, habituality is argued to include a quantifier over occasions that yields the reading of reference to multiple occasions. In contrast, continuous viewpoint seems to not involve any quantifier over particular occasions. This is why no interpretation of any actual instantiation ensues. Revised structures for progressive and continuous viewpoint follow below. While the progressive has a quantifier over occasions with the cardinality of one, the continuous lack a quantifier altogether.

(56)

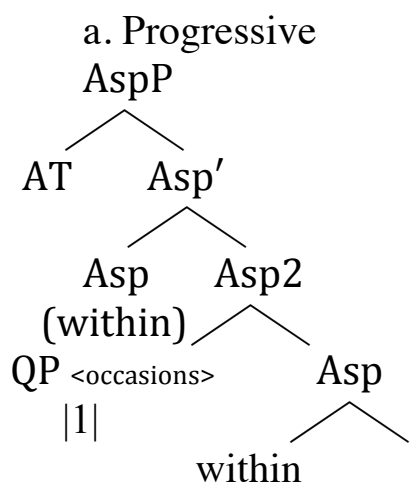

b. Continuous

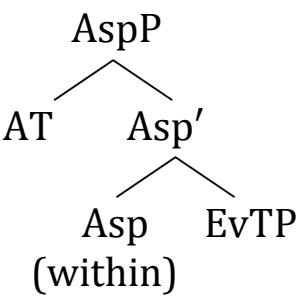

The syntax and semantics proposed for the aspectual attitudinal readings is the one in (56b) different from the one to be proposed for habituals below. In this respect, the proposal developed here differs from other authors' perspective (e.g. Bertinetto \& Lenci 2012), where the differences between habituals and gnomic sentences such as attitudinals are accounted for by alluding to pragmatic factors. I take it that if differences such as the availability of agency oriented adverbials can be observed, a different syntax-semantics is underlying. ${ }^{25}$

\footnotetext{
${ }^{25}$ In addition to the differences mentioned above (e.g. availability of agency), attitudinals and habituals show overt differences in languages such as in African American English. As described in Green (2000), (i) has an attitudinal interpretation, namely, 'there is the possibility that Bruce can sing; he does not object to singing', while (ii) has a habitual one: 'Bruce actually sings (usually sings) on particular occasions'.

(i) Bruce sing.

(ii) Bruce be singing.
} 


\section{The construction of habituality}

There is another interpretation that the Imperfect can have in Spanish and many other languages: the habitual one. In this section I put forth a proposal regarding its encoding in the semantic-syntactic model adopted.

We speak of a habitual reading when we understand that we are making reference to a situation pattern, to what is often called a "non-accidental generalization" (Bonomi 1997, 1998; Bertinetto 2000; Menéndez-Benito 2002). The fundamental intuition behind a habitual reading is that the eventuality at hand happens more than once and the frequency with which it happens is high enough to consider it as non-occasional. Following previous literature I will describe habituality as the reference to a plural number of instantiations of an event (e.g. Bertinetto 2000, 2012; Ferreira 2005; Arche 2006) that happen at regular intervals with respect to a norm according to which they are supposed to occur. This reading is available with all sorts of predicates (states and non-states) as shown below by the compatibility of the imperfect with a habitual adverbial (usually): states (57), activities (58), accomplishments (59) and achievements (60):

(57) Normalmente Daniel estaba enfermo en invierno.

Usually Daniel be-impf.3ps ill in the winter

(58) Normalmente Daniel caminaba por el parque. Usually Daniel walk-impf.3ps in the park Normalmente Daniel dibujaba un castillo. Usually Daniel draw- impf.3ps a castle Normalmente Daniel llegaba a la meta sin problemas. Usually Daniel arrive- impf.3ps at the goal with no problems.

Here I argue that the habitual reading is a by-product of the combination of a verbal predicate with a specific functional structure. In particular, I argue that habituality emerges in a complex structure where a perfective head is also present. In what follows I discuss the semantics of habituality and its syntax. I furthermore argue that the view of habituality as a coercive tool affecting situation aspect properties (turning telic predicates into atelic) is not tenable.

\subsection{The semantics of habituality}

With other authors I consider that the reading of plurality of occasions characteristic of the habitual reading originates in the presence of a quantifier located in the Aspect projection. Bonomi (1997), Verkuyl (1999), Cipria \& Roberts (2000), Bertinetto (2000, 2012), Menéndez-Benito (2002), or Ferreira (2005), among others, consider that the quantifier involved in habituality is a quantifier yielding plurality. For most of these authors such a quantifier is considered to be a universal quantifier, which brings the issue of formalizing the allowance for exceptions, as the failure of the whole set of occasions to be instantiated does not invalidate the interpretation of the eventuality as habitual. Instead, I will argue, following Arche (2006), that the quantifier involved in habitual quantification is one of the family of "many" from the nominal realm. Such a quantifier is a proportional quantifier by nature, which has the advantage of allowing us to take into account the relation between the predicate in question 
and the average amount such a situation takes place in a specific context (Westerståhl 1984; Partee, ter Meulen \& Wall 1993).

I argue that the habitual quantifier refers not plainly to a plural number of occasions but to a number of occasions considered "average." The average ratio relevant in each case is necessarily established with the help of contextual information. The number of times considered average for, for example, smoking might be different from the number of times considered average for traveling to a foreign city. A given eventuality can be described as habitual if the number of occasions on which the eventuality gets substantiated is the approximate average ratio of such an eventuality, statistically established within certain social and habit parameters. That is, unlike quantifiers such as (proportional) many, the habitual quantifier does not denote an amount of instances "greater" than the ratio but an amount that represents "the ratio itself" or is "close to the ratio," where the margins to consider a certain amount of times significantly close to the ratio may be flexible and subject to other pragmatic considerations. Similar to the representation of many given by Partee, ter Meulen and Wall (1993) in (61), I propose the interpretation of the habitual quantifier (Hab) as in (62), following Arche (2006). The number of students who passed can be described as "many" if the cardinality of students who passed (that is, A B) is greater than the cardinality of students by a contextual ("norm") parameter (c), where the contextual parameter captures the average ratio relevant in this case. Just as the interpretation of quantifiers like many is affected by contextual information, so is the interpretation of the habitual quantifier. A certain event can be described as habitual if the cardinality of occasions that a subject performs it $(|(A \cap B)|)$ is fairly close to the cardinality of times the event takes place by a contextual parameter $(\mathrm{c})$.

(61) Many students passed.

Many $\mathrm{AB}=$ many $\mathrm{A}|(\mathrm{A} \cap \mathrm{B})|>\mathrm{c} \cdot|\mathrm{A}|$

where $\mathrm{A}$ \{students and $\mathrm{B}$ \{pass $\}$

Juan fumaba.

Juan smoke- impf.3ps

'Juan smoked/ used to smoke'

$\mathrm{Hab} \mathrm{AB}=\mathrm{Hab} \mathrm{B}|(\mathrm{A} \cap \mathrm{B})| \simeq \mathrm{c} \cdot|\mathrm{B}|$

where $\mathrm{A}\{$ Juan $\}$ and $\mathrm{B}$ \{smoke\}

As before with many, the contextual parameter captures the average ratio relevant in each case. ${ }^{26}$ Concurring with Verkuyl (1999) and Bertinetto (2000) I consider that each individual instance of the eventuality is to be understood as perfective in itself. Habituals refer to a plurality of occasions that have already taken place, that are finished; to a plurality of eventualities that can be referred to as perfective individually and whose individual duration can be measured (e.g. with a foradverbial). The contrast below shows again how for-adverbials require the perfective and exclude the imperfect. The sentence in (63) is bad on the continuous reading of the imperfect, made salient by the clausal modifier. The one in the perfective is fine.

\footnotetext{
${ }^{26}$ Perfective forms can have an iterative reading. I argue that this, however, is different from the habitual reading. The quantifier involved in each form has different properties. While iteration is part of habitual frequency, habitual frequency is not just iteration, but iteration forming a particular pattern. This depends on several factors of heterogenous nature, such as the kind of eventuality in point and a contextually established pattern of frequency. For further discussion see Arche 2006, Bertinetto \& Lenci 2012, among others.
} 
(63) visité

*Daniel estaba enfermo durante una semana cuando lo

Daniel be-Impf.3ps ill for a week when him visited-I.

'Daniel was ill for a week when I visited him'

Daniel estuvo enfermo durante una semana.

Daniel be-Pfve.3ps ill for a week

However, the imperfect can be okay with a for-adverbial if a habitual reading is induced, for example by the addition of a habitual adverbial. The adverbial compatibility suggests that the perfective is somehow present, given that it is visible for modification:

Daniel estaba enfermo durante una semana todos los inviernos. Daniel be-Impf.3ps ill for a week every winter

A habitual sentence refers to the situation schematized in (66) and glossed in (67):

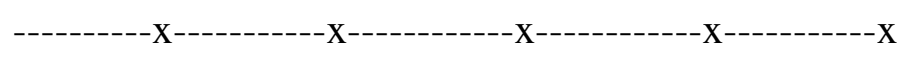

$$
\text { week }+ \text { Daniel be-Pfve.3ps ill for a week }+\ldots
$$

Each cross stands for an eventuality of having been sick for a week. Each happening is understood as finished. I argue that this is the reason why formodifiers combine with the imperfect form only under a habitual reading. Thus, it seems that the individual instances are grammatically relevant as well, as they can be modified by adverbials (e.g.for-time). If the event time corresponding to each instance can be modified, this must be because it is visible at some point of the derivation. Interestingly, this is also possible in the present tense:

Daniel nada durante una hora todos los días.

Daniel swims for an hour every day

This suggests that perfectivity should not be understood as opposite to habituality, as some authors (e.g. Giorgi \& Pianesi, 1997) have suggested, but, rather, as a part of it. Even in English, where Giorgi and Pianesi (op. cit.) argue that state verbs are not linked to perfectivity but to a generic operator, perfectivity can be argued to be in place with the habitual interpretation. The sentence below contains a state predicate and two kinds of aspectual modifiers: one marking habituality, every winter, and another one marking the duration of each instantiation of the eventuality, for a week. As discussed above, the whole duration of an eventuality is susceptible of being specified only when perfective aspect is present. The good formation of the sentence (69) containing a for-adverbial suggests that perfectivity must be syntactically present, since the whole duration of the eventuality can be specified. Since modification that only combines with the perfective can coappear with habitual modification, it is clear that both kinds of aspectual content coexist in the syntactic and semantic representation of the clause.

$$
\text { Daniel was ill for a week every winter. }
$$


Examples like this also suggest that habituality and stativity must be analyzed separately, contrary to some accounts (Chierchia 1995, Giorgi \& Pianesi 1997). As observed, stativity without habituality does not license for-adverbials, which reinforces the idea they are not the same creatures. If they had the same properties, the modifiers that could be combined with them would be the same, contrary to the facts. If (70) is not understood as a habitual (maybe by understanding a silent habitual modifier or recovering one from the context) the sentence is not possible.

(70) *Daniel estaba enfermo durante una semana.

Daniel was-Impf.3ps ill for a week

Regarding the relation of habituality and the situation aspect properties of the predicate, I argue that habituality does not alter the properties of predicates. The syntactic structure giving rise to habituality does not, for example, turn telic events into states, as has been claimed in the literature (e.g. de Swart 1998). Usually, the evidence that is brought up in this regard is the good combination of habituals with for-adverbials. However, as discussed above, the good combination with for-time adverbials can be explained by the perfective head involved in the habitual. That is, it is not that the habitual "changes" the nature of the predicate. The fact that the heterogeneous properties of the predicate are not lost under habitual viewpoint can be proved by the availability of the in-time adverbial. A version of the well-known example provided by de Swart (1998) is below:

$$
\begin{aligned}
& \text { Juan tocaba la sonata en cinco minutos normalmente. } \\
& \text { Juan play-Impf.3ps the sonata in five minutes usually } \\
& \text { 'Juan usually played the sonata in five minutes' }
\end{aligned}
$$

The possible co-occurrence of the in-time adverbial and the habitual adverbial suggests that telicity and habituality can coexist and that the adverbials modify different parts of the structure. It also shows that the Imperfect form in Spanish is not necessarily atelic, as Cipriá and Roberts (2000) claim.

\subsection{The syntax of habituality}

Thus, according to the previous discussion, it seems that the formalization of habituality should include several elements: (i) a quantifier of occasions to capture the component of iteration contained in habitual readings; (ii) a head to capture the fact that each instance of the eventuality at hand is understood as 'finished'; and (iii) an ordering predicate of the sort of "within", by which the AT is ordered within an interval that contains the plurality of perfective instantiations. I will propose a structure that attempts to capture all this in what follows. With the aim of identifying all the elements involved, I will work with examples with modifiers. In the example given below, the AT is the one restricted by cuando era pequeña 'when she was young' and durante cinco horas 'for five hours' is the adverbial modifying each individual instance (perfective, finished).

(72) Cuando era pequeña Marta nadaba durante cinco horas.

When was-impf.3ps young Marta swim-Impf.3ps for five hours 
'When she was young Marta used to swim for five hours'

That is, habituality seems to involve a complex relation between intervals: within and overlap. The ordering predicate within does not prevent the plurality of occasions (of swimming) to occur also before or after the Assertion Time. That is, Marta may have swum for five hours before the period of time referred to by the Assertion Time, or may continue swimming for five hours after it. The claim made in the sentence of the example regards the period of time restricted by when I was young. The adverbial for five hours restricts the duration of the interval each one of the instantiations of the eventuality takes place. What needs to be further defined is whether it is a modifier restricting an AT or an ET. Demirdache and Uribe-Etxebarria (2004) analyze durational adverbials of the sort of for five hours or in five hours as restrictors of the AT. In their analysis, when the perfective is involved, the AT amounts to the ET, and the aspect head is analyzed as null in content, ${ }^{27}$ which makes the election of what these adverbials modify difficult to elucidate. Here I argue that the adverbial durante cinco horas 'for five hours' modifies the ET since it does not seem that it can be considered as a recursive restriction of the AT (73). ${ }^{28}$ I analyze (72) taking the ones in (74), containing more than one for-phrase, and (75), showing that for-phrases and in-phrases can cooccur into account. Sentences in (74) show that the adverbial measuring the individual instantiation (durante una hora 'for an hour') prefers to sit next to the verb (74a), (74c); if we separate the adverbial from the verb, either by bringing it to the front $(74 \mathrm{~b})$ or by pre-posing it to the adverbial measuring the individual instantiation of the event (74d), the sentence becomes degraded. The interpretation of sentences (74a) and (74b) is that where for the span of time of an hour there are several occurrences of castle-drawings, each one of which was completed within the span of a minute. That is, the whole span of time is measured by the for-adverbial and the duration of each individual instance is measured by the in-adverbial. The clear-cut oddity of (74c) and (74d) suggests that, although these adverbials can co-occur, they occupy different positions. The adverbial that measures the duration of each instance is preferred in a position next to the verb. Interestingly, same thing happens with homogeneous predicates.

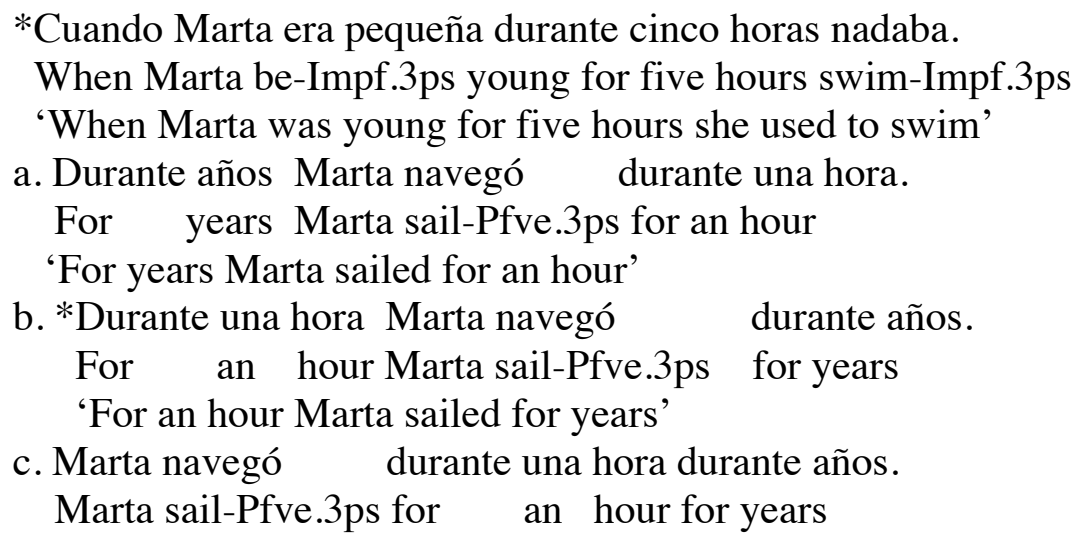

\footnotetext{
${ }^{27}$ The result is similar to what is obtained with the overlap head, since the AT and ET totally coincide.

${ }^{28}$ An alternative solution would be to think that, since there is more than one Aspect head, each adverbial modifies different ATs. I discard this option based on the analysis of cases such as (74a) and $(74 \mathrm{c})$, where it seems clear that one adverbial modifies the duration of the particular instance. Note, however, that the only portion of the EvT that becomes visible for semantic modification is the one that coincides with the AT.
} 
'Marta sailed for an hour for years'

d. ??Marta navegó durante años durante una hora.

Marta sail-Pfve.3ps for years for an hour

'Marta sailed for years for an hour'

a. Marta dibujó castillos en un minuto durante una hora.

Marta draw-Pfve.3ps castles in a minute for an hour

'Marta drew castles in a minute for an hour'

b. Durante una hora Marta dibujó castillos en un minuto

For an hour Marta draw-Pfve.3ps castles in a minute

'For an hour Marta drew castles in a minute'

c. *En un minuto Marta dibujó castillos durante una hora

In a minute Marta draw-Pfve.3ps castles for an hour

'In a minute Marta drew castles for an hour'

minuto.

d. *Marta dibujó un castillo durante una hora en un

Marta draw-Pfve.3ps a castle for an hour in a minute

'Marta drew a castle for an hour in a minute'

We can take all these contrasts to mean that the adverbial measuring the duration of each instantiation modifies the Event-Time. In turn, the adverbial denoting the period of time during which the instantiations take place modifies the AT:

(76)

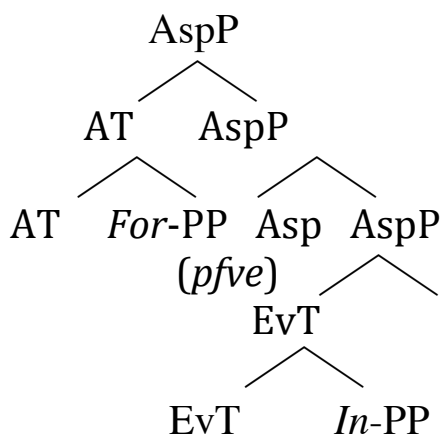

With all this in mind, a structure for habituality is attempted below, containing two aspect heads with two different ordering predicates. The structure of (77) reads: the AT is within an interval that contains a plural number of intervals ${ }^{29}$ that overlap with event times of swimming. The duration of such overlap relation is five hours. What clusters the habitual together with the other readings of the imperfect is the predicate within that appears in the upper Aspect head and has a reflex on inflection. The aspect head capturing the perfectivity of each instance does not receive any morphological form in Spanish, but it is visible for the semantics component, as it can be modified -- recall that only when the perfective is present is a for-time adverbial viable. The adverbial cuando era pequeña 'when I was young' acts as a restrictor of the AT of the clause; the AT is within an interval containing a plurality of occasions which are interpreted as perfective

${ }^{29}$ For Klein (1994) the habitual interpretation is based on a plurality of Assertion Times (Topic Times). In line with Arche (2006) I consider that the quantificational information is independent from the sentential Assertion Time, which is subject to discourse by nature and changes accordingly. 
each, hence the need of another aspect head. Each instantiation of the eventuality is modified by durante cinco horas 'for five hours'.

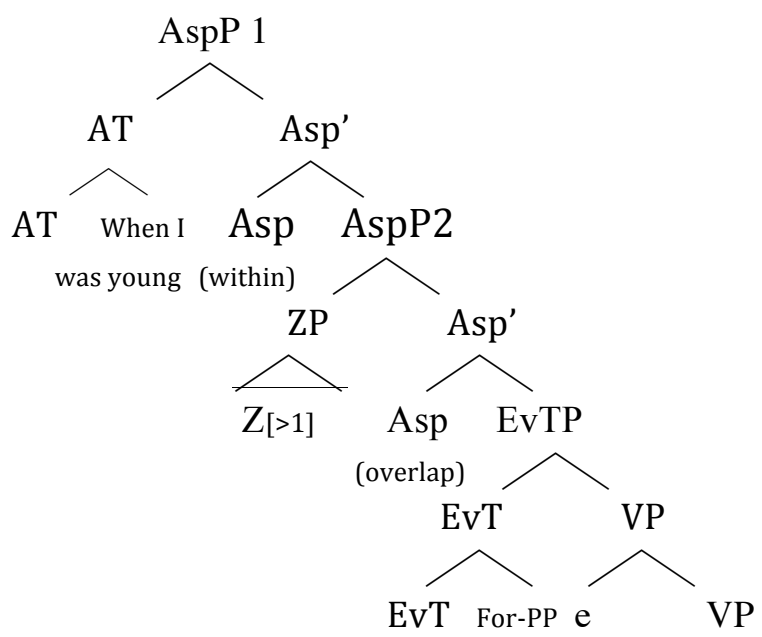

\section{A note on cross-linguistic considerations about the semantics and morpho-syntax of Aspect.}

In this section I would like to argue that absence of dedicated inflectional marking does not mean that the semantics of the imperfective in contrast to perfective is non-existent, concurring with what other authors (e.g. Boogaart 1999; Bertinetto 2000) have pointed out. As discussed above, in Spanish the Imperfect inflected form corresponds to readings such as (imperfective) progressive, habitual, continuous and characterizing; the Perfective form can correspond to perfective or perfective progressive. In other languages, such as for example English, the distributions of these readings differ slightly. English does not have different dedicated paradigms to mark aspectual differences and the question that arises is whether the past tense form may be a unique form to represent different semantic and syntactic aspectual structures.

Different authors have argued that past tense in English is perfective. Brinton (1988) and Smith (1991) argue that all instances of past tense in English are perfective. They add that the interpretation as 'finished' is an inference depending on situation aspect properties, as state verbs do not seem to comply with that given description at all times. Giorgi \& Pianesi (1997) argue that only eventive verbs have a perfective interpretation in the past. In what follows I add to the discussion that shows that, as a matter of fact, English state verbs are not always imperfective and that event verbs in past tense forms can have imperfective readings too. I will argue that the past form in English is a case of ambiguity between perfective/imperfective interpretation, involving imperfective and perfective semantic and syntactic representations.

As has been pointed out by other authors (e.g. Boogaart 1999), when the predicate is a state English past is able to have two readings, imperfect and perfective. This is shown by the following cases:

John was in London when I bumped into him. 
Example (78) illustrates the imperfect reading, in which the modified AT (when I bumped into him) is contained within the interval of John's being in London. Sentence (79), with the for-adverbial, secures an interpretation in which the interval corresponding to John's being in London is finished. That is, it represents what is known as perfective. The subsequent question is what the relation is between the meanings and the form. The possibilities are, at least, two: either there are two different syntactic-semantic structures, or there is just one structure that is vague with respect to aspectual interpretation. If the past form were a case of ambiguity, it would yield only one meaning in a specific context. Imperfect or perfective interpretations would not be true of the same context. If it were a case of vagueness, the two meanings could be simultaneously true in the same context of the past form. To discriminate between ambiguity and vagueness, I will analyze the interpretation of past in sentences containing so-anaphora. ${ }^{30}$ If only one reading is retrievable in the part containing ellipsis, ambiguity can be argued to be in place, since it will be an indication that a specific content in the head was present. If both readings are available under ellipsis, that would be an indication for vagueness.

In the example below I have included adverbials with opposite aspectual requirements: a for-adverbial, which secures a perfective interpretation in the first conjunct of the sentence, and an adverbial clause (when I bumped into him) acting as a modifier of the assertion time, which favors an imperfective reading in the second conjunct of the sentence. As can be seen, the for-adverbial is incompatible with the imperfective reading of the part containing the elided material and it produces an anomalous result:

(80) \#John was in London for 24 hours and so was Bill when I bumped into him.

The anomaly is explained because the past in the second conjunct, with the elided $\mathrm{VP}$, cannot have a reading where it is interpreted as anything other than perfective. ${ }^{31}$ This shows that the English past tense is a case of real ambiguity where one form corresponds to two different syntactic-semantic representations. Thus, it can be concluded that in English, the difference between imperfective and perfective exists in the semantics and the syntax but has only one morphological form. The perfective/imperfective distinction is not suspended, but it is just expressed via the same morpheme used for the perfective.

If past tense is ambiguous between imperfective/perfective, other readings related to structures different from the perfective are expected also with event verbs, such as ability or habitual readings. As a matter of fact, English past tensed event predicates can also bear such a reading as shown in the examples below:

\footnotetext{
${ }^{30}$ I want to thank Tim Stowell for discussing this issue with me.

${ }^{31}$ The same anomaly is in \#John was in London for 24 hours when I bumped into him. There is one possible interpretation for this sentence, though, which is visible if we continue the sentence by saying "John was in London for 24 hours when I bumped into him, but he changed his mind and left earlier".
} 
(81) My grandfather never studied languages properly but he read French, Chinese and German.

Another typical imperfective reading that English eventive verbs have in the past is the habitual reading. According to native speakers, as shown below, English past tense is compatible with adverbs such a "usually" (80), which in languages that show imperfective marking combines with the imperfective rather that with the perfective (81):

Usually my granddad strolled in the park

Normalmente mi abuelo paseaba/*paseó por el parque

Usually my granddad stroll-impfve.3ps/stroll-pfve.3ps in the park

All these facts point to the conclusion that English past tense can have imperfective syntax and semantics. The only interpretation that does not seem to arise from past inflection is the imperfective progressive. English (83) is equivalent to the Spanish (84). Interestingly, though, past tense forms seem unable to yield an imperfective progressive interpretation. A sentence like (85) cannot mean that John was in the process of drawing a castle when I visited him (86).

(84) John drew a castle for an hour.

(85) John estuvo dibujando un castillo durante una hora "John was-pfve.3ps drawing a castle for an hour'

(86) John drew a castle when I visited him.

(87) \# John was in the process of drawing a castle when I visited him.

\section{Summary and conclusions}

In this paper I have argued that the contribution of the viewpoint aspect heads is "constructive" and does not modify the event description by mutating the properties of predicates. I have revisited classical issues where the semantics of situation aspect properties have been understood to be at odds with viewpoint aspect properties and, in essence, I have argued that predicates keep their properties throughout. This does not amount to saying that any combination is possible (e.g. any state with the progressive); this means that when a combination is given in the syntax, viewpoint aspect heads do not alter the nature of the predicate. I have argued that different imperfective readings (e.g. progressive, attitudinal, habitual) emerge from a specific syntax-semantics based on intervalordering predicates and quantifiers and I have discussed the relations between such syntactic structures and their morphological forms. I have also shown that the progressive cannot be associated with the imperfective only and must be deconstructed. I have suggested that a syntax-semantics corresponding to perfective progressives underlie Spanish Perfective accomplishments with nonculminating readings, which situates the account of lack of completion within the realm of viewpoint aspect. Correspondingly, culminating readings are proposed to be a by-product of an implicature process based on assuming that the amount of information provided is the maximum (Grice 1975). Regarding the correlations between the syntactic-semantic representation and the morphology I have argued 
that they vary across languages; the fact that only one form is shown morphologically (e.g. English past) does not mean that the language does not have different semantic components represented in the syntax.

The proposal that homo/heterogeneity is a property that depends on syntactic structure and that it does not correlate with given aspectual forms casts doubt on the correlation very often assumed between (a)telicity and (im)perfectivity. This has consequences for the analysis of different issues that at the moment mostly rely on this correlation, such as the acquisition of viewpoint aspect forms. First and second language acquisition studies often show that the relationship between viewpoint and situation aspect gives inconclusive results (see Salaberry 2002, 2008 and references therein, among others). If the analysis explored in this paper is on the right track, the alleged rationale for the route of the acquisition of the imperfective/perfective contrast, based on situation aspectviewpoint correlations, should be taken cum grano salis and revisited.

\section{Acknowledgments}

I want to thank Tim Stowell, Hamida Demirdache, Myriam Uribe-Etxebarria, Rafael Marín, Ivano Caponigro, the audience of the Semantics Babble at the department of Linguistics at the University California San Diego, Olga Borik, Marcel den Dikken, Jürgen Bohnemeyer, Daniel Altshuler and two anonymous reviewers for their insightful comments on previous versions of this paper. Errors are all my own.

\section{References}

Arche, María J. 2006. Individuals in Time. Tense, aspect and the individual/stage distinction. Amsterdam/Philadelphia: John Benjamins.

Bach, Emonds. 1986. The Algebra of Events, Linguistic and Philosophy 9: 5-16.

Bar-el, Leora, Henry Davis and Lisa Matthewson. 2005. On non-Culminating Accomplishments, Proceedings of the North Eastern Linguistics Society 35. Amherst, MA: GLSA, pp. 87-103.

Bertinetto, Pier Marco. 2000. The progressive in Romance, as compared to English, in 0. Dahl (ed.) Tense and aspect in the languages of Europe, Berlin: Mouton de Gruyter, pp. 559-604.

1994. Statives, Progressives and Habituals. Linguistics, 32: 391-423.

Bertinetto, Pier Marco and Alessandro Lenci. 2012. Habituality, pluractionality and imperfectivity. In Robert I. Binnik (ed.), The Oxford Handbook of Tense and Aspect, Oxford: Oxford University Press, pp. 852-880.

Bertinetto, Pier Marco, Karen H. Ebert and Casper de Groot. 2000. The progressive in Europe, in Östen Dahl (ed.) Tense and aspect in the languages of Europe, Berlin: Mouton de Gruyter, pp. 517-558.

Bonomi, Andrea. 1997. The Progressive and the structure of events. Journal of Semantics 14: 173-205.

Boogaart, Ronny. 1999. Aspect and Temporal Ordering. A contrastive analysis of Dutch and English. The Hague: Holland Academic Graphics.

Borer, Hagit. to appear. Structuring Sense (vol III). Oxford: Oxford University Press. 2005. Structuring Sense. (Vol II). Oxford: Oxford University Press.

Bohnemeyer, Jürgen. and M. Swift. 2004. Event realization and default aspect. Linguistics and Philosophy 27, 3: 263-296.

Borik, Olga and Tanya Reinhart. 2004. Telicity and Perfectivity: Two Independent Systems. In László Hunyadi, György Rákosi and Enikő Tóth (eds.) Proceedings of

LOLA 8 (Symposium on Logic and Language), pp. 13-34. Debrecen: Hungary.

Brinton, Laurel. 1988. The Development of English Aspectual Systems. Cambridge: CUP.

Carlson, Greg. 1977. Reference to Kinds in English. Ph.D. dissertation, University of Massachusetts, Amherst. 
Cipriá, Alicia and Craige Roberts. 2000. Spanish imperfecto and pretérito: truth conditions and aktionsart effects in situation semantics. Natural Language Semantics 8: 297347.

Demirdache, Hamida and Myriam Uribe-Etxebarria. 2011. Aspect and Temporal Anaphora. Paper presented at Chronos, Birmingham, April 2011.

2007. The Syntax of Time Arguments. Lingua 117: 330-366.

2004. The Syntax of Time Adverbs, in Jacqueline Guéron and Jacqueline Lecarme (eds.), The Syntax of Time, Cambridge, MIT Press: 217-234.

2000. The Primitives of Temporal Relations. In R. Martin (ed.), Step by Step: Essays on Minimalist Syntax in Honor of Howard Lasnik, 157-186. Cambridge, Mass.: MIT Press.

Deo, Ashwini. 2009. Unifying the imperfective and the progressive: partitions as quantificational domains. Linguistics \& Philosophy 32, 5: 475-521.

Dowty, David. 1979. Word Meaning and Montague Grammar. Dordrecht: Reidel.

Enç, Mürvet. 1987. Anchoring conditions for tense. Linguistic Inquiry 18:633-657.

Ferreira, Marcelo. 2005. Event Quantifiecation and Plurality. PhD. Dissertation, MIT.

Fintel, Kai von. (1994): Restrictions on Quantifier Domains, Ph.D. dissertation, UMass., Amherst.

García Gernández, Luis. 1999. Los complementos adverbiales temporales. In Ignacio Bosque and Violeta Demonte (eds.), Gramática descriptiva de la lengua española, Madrid: Espasa Calpe, pp. 3129-3208.

Garey, Howard B. 1957. Verbal Aspect in French. Language 33, 2 : 91-110.

Giorgi, Alessandra and Fabio Pianesi. 1997. Tense and Aspect. From Semantics to Morphosyntax. Oxford: OUP.

Green, Lisa. 2000. Aspectual be-type constructions and coercion in African American English. Natural Language Semantics 8: 1-25.

Grice, Herbert P. 1975. Logic and conversation. In P. Cole and J. L. Morgan, (eds.), Syntax and Semantics 3: Speech Acts, p. 41-58. San Diego, CA: Academic Press.

Herweg, Michael. 1991. Perfective and imperfective aspect and the theory of events and states. Linguistics 29: 969-1010.

Higginbotham, James. 2004. The English Progressive, in Jacqueline Guéron and Jacqueline Lecarme (eds.), The Syntax of Time, Cambridge, MIT Press, p. 329-358.

Hinrichs, Erhard. 1986. Temporal Anaphora and Discourses of English. Linguistics and Philosophy 9: 63-82.

Kamp, Hans and Christian Rohrer. 1983. Tense in texts, in Rainer Bäerle, Christoph Schwarze and Arnim von Stechow (eds.), Meaning, Use and Interpretation of Language, Berlin, de Gruyter: 250-269.

Kearns, Katherine. 1991. The semantics of the English progressive. PhD Diss, MIT.

Kennedy, Christopher and Beth Levin. 2008. 'Measure of change: The adjectival core of verbs of variable telicity'. In McNally, Louise and Christopher Kennedy (eds.), Adjectives and Adverbs: Syntax, Semantics, Discourse. Oxford: Oxford University Press.

Klein, Wolfgang. 2009. How time is encoded. In W. Klein, \& P. Li (Eds.), The expression of time (pp. 39-82). Berlin: Mouton de Gruyter.

1994. Time in Language. London: Routledge.

Klein, Wolfgang, Ping Li and Henriette Hendriks. 2000. Natural Language \& Linguistic Theory 18: $723-770$.

Koenig, Jean-Pierre and Liangcheng Chief. 2008. Scalarity and State-Changes in Mandarin, Hindi, Tamil, and Thai, in Empirical Issues in Syntax and Semantics 7, 0. Bonami and P. Cabredo Hofherr (eds.), pp.241-262.

Koenig, Jean-Pierre and Nuttanart Muansuwan. 2000. How to end without ever finishing: Thai semi-perfective markers. Journal of Semantics 17: 147-184.

Krifka, Manfred, Francis. J. Pelletier, Greg Carlson, A. ter Meulen, G. Link, and G. Chierchia. 1995. Genericity: An Introduction, in G. N. Carlson and F. J. Pelletier (eds.), The Generic Book, pp. 1-124. Chicago: The University of Chicago Press.

Lakoff, George. 1966. Stative Verbs and Adjectives in English [Harvard Computational Laboratory Report NSF-17]. Cambridge, MA: Harvard University.

Landman, Fred. 1992. The progressive. Natural Language Semantics 1:1-32.

Lenci, Alessandro. 1995. The semantic representation of non-quantificational habituals, in Pier Marco Bertinetto, Valentina Bianchi, James Higginbotham, Mario Squartini (eds.), Temporal Reference Aspect and Actionality. Vol 1: Semantic and Syntactic Perspectives, Torino, Rosenberg \& Sellier: 143-158. 
Link, Godehard. 1983. The Logical Analysis of Plurals and Mass Terms. A Lattice-Theoretic Approach, in Rainer Bäerle, Christoph Schwarze and Arnim von Stechow (eds.), Meaning, Use and Interpretation of Language, Berlin, de Gruyter: 302-323.

Menéndez-Benito, Paula. 2000. Aspect and adverbial quantification in Spanish. In Mako Hirotani (ed.), Proceedings of the 32nd meeting of the North East Linguistic Society, University of Massachusetts, Amherst: GLSA, 365-382.

Moens, Marc. 1987. Tense, Aspect and Temporal Reference. Ph.D. Dissertation, University of Edinburgh.

Musan, Renata. 1997. Tense, predicates, and lifetime effects. Natural Language Semantics 5: 271-301.

Partee, Barbara, Alice ter Meulen and Robert Wall. 1993. Mathematical Methods in Linguistics. Dordrecht: Kluwer.

Parsons, Terence. 1990. Events in the Semantics of English. Cambridge, MA: MIT Press.

Ramchand, Gillian. 2008. Verb Meaning and the Lexicon: A First-Phase Syntax. Cambridge: Cambridge University Press.

Reichenbach, Hans. 1947. Elements of Symbolic Logic. New York: The Free Press.

Salaberry, Rafael. 2008. Marking Past Tense in Second Language Acquisition: A theoretical model. London/ New York: Continuum Books.

Salaberry, Rafael and Yasuhiro Shirai. 2002. Tense-Aspect Morphology in L2 Acquisition, Amsterdam: John Benjamins.

Schubert, Lenhart K. and Francis J. Pelletier: 1989, 'Generically Speaking, or Using Discourse

Representation Theory to Interpret Generics', in G. Chierchia, B. H. Partee and R. Turner (eds.), Properties, Types and Meaning, Vol 2: Semantic Issues, pp. 193-268. Kluwer, Dordrecht.

Smith, Carlota. 1991. The Parameter of Aspect. Dordrecht: Kluwer.

Stowell, Timothy A. 2007. The Syntactic Expression of Tense. Lingua 117: 437-463. 1996. The phrase-structure of tense. In Phrase Structure and The Lexicon [Studies in Natural Language and Linguistic Theory], J. Rooryck and L. Zaring (eds.), 277-291. Dordrecht: Kluwer.

1993. Syntax of tense. Ms., University of California, Los Angeles.

de Swart, Helen. 1998. Aspect Shift and Coercion. Natural Language and Linguistic Theory 16: 347-385.

Tatevosov, Sergei. 2008. Subevental structure and non-culmination. In O. Bonami \& P. Cabredo Hofherr (eds.), Emperical Issues in Syntax and Semantics 7: 393-422.

Verkuyl, Henk. 1999. Tense, Aspect and Aspectual Composition. In Topics in South Slavic Syntax and Semantics, L. Hellan and M. Dimitrova-Vulchanova (eds.), Amsterdam: John Benjamins, pp.125-162.

Vlach, Frank. 1981. The semantics of the progressive. In P. Tedeschi, (ed.), Syntax and Semantics 14: Tense and Aspect. New York: Academic Press.

Westerståhl, Dag. 1984. Determiners and context sets. In Generalized Quantifiers in Natural Language, J. van Benthem and A. ter Meulen (eds.), 45-71. Dordrecht: Foris.

Zagona, Karen. 1990. Times as temporal argument structure. Ms., University of Washington, Seattle.

Zemach, Eddy. 1975. On the adequacy of a type ontology. Synthese 31:509-515.

Zucchi, Alessandro. 1999. Incomplete events, intensionality and imperfective aspect. Natural Language Semantics 7: 179-215. 